\title{
El conjunto de fauna menor del sitio La Modesta: un aporte al estudio de la subsistencia durante el Holoceno medio en la transición pampeano-patagónica oriental (Buenos Aires, Argentina)
}

Ana P. Alcaráz*
Recibido:

9 de marzo de 2019

Aceptado:

2 de septiembre de 2019

\section{Resumen}

En este trabajo se exponen los resultados obtenidos de los análisis realizados sobre los restos de fauna menor $(<15 \mathrm{~kg}$ ) recuperados en superficie y estratigrafía del sitio La Modesta (transición pampeano-patagónica oriental, provincia de Buenos Aires). Este sitio se localiza en un contexto de dunas, próximo a un paleocauce del río Colorado y distante a $60 \mathrm{~km}$ de la costa Atlántica. Los fechados radiocarbónicos sitúan a las ocupaciones humanas en el Holoceno medio (ca. 5900-5600 años AP). Los estudios realizados muestran que el conjunto faunístico es producto de complejas historias tafonómicas y que la presencia de los taxa identificados responde a diversas causas. Además de los peces fluviales, otras especies de fauna menor, como Myocastor coypus, aves medianas y posiblemente armadillos, habrían contribuido a la dieta de las poblaciones humanas. Esta información, sumada a la ya generada para el sitio (análisis de las especies de tamaño mayor, isótopos estables) contribuye a generar una primera aproximación acerca de la subsistencia de las poblaciones cazadoras-recolectoras para un momento en el que no se contaba con dicha información en el área de estudio.

The small-vertebrate assemblage of La Modesta site: A contribution to subsistence studies during the Middle Holocene in the Eastern Pampa-Patagonia transition (Buenos Aires, Argentina)

\footnotetext{
Abstract

This work presents the results from the analysis of the small-sized vertebrate remains recovered from the surface and stratigraphic contexts of La Modesta site (eastern PampaPatagonia transition, Buenos Aires province). This site is located in an area of deflated dunes, close to a paleochannel of the Colorado River, and $60 \mathrm{~km}$ away from the Atlantic coast. Radiocarbon dates place the human occupations in the Middle Holocene (ca. 59005600 years BP). Our analyses show that the faunal assemblage is the result of complex

* Instituto de Investigaciones Arqueológicas y Paleontológicas del Cuaternario Pampeano (INCUAPA) - CONICET, Facultad de Ciencias Sociales, Universidad Nacional del Centro de la Provincia de Buenos Aires (UNICEN). Av. Del Valle 5737 (CP B740oJWI) Olavarría, Buenos Aires, Argentina. E-mail: aalcaraz@soc.unicen.edu.ar
}

\section{Palabras clave}

Holoceno medio Curso inferior del río Colorado Contextos superficiales Estudios zooarqueológicos Tafonomía
Keywords

Middle Holocene Lower Colorado River Surface contexts Zooarchaeological studies Taphonomy 
taphonomic histories, and that the presence of the identified species is a consequence of different causes. Results indicate that, in addition to perch, other species, such as Myocastor coypus, medium-sized birds, and possibly armadillos, would have contributed to the diet of the human populations. This information, together with the data already available from the site (analysis of the larger-sized species, and stable isotopes), represent the first approaches to hunter-gatherers subsistence during a period that lacked such information in the study area.

\section{Introducción}

Los estudios zooarqueológicos y tafonómicos sobre los restos de fauna menor brindan la posibilidad de conocer diversos aspectos vinculados a la conducta de las poblaciones humanas, como así también del entorno en el cual tuvieron lugar las ocupaciones (Andrews, 1990; Stahl, 1996). En el área de la transición pampeano patagónica oriental el estudio de este registro se ha focalizado en sitios con cronologías del Holoceno tardío (Alcaráz, 2015a, 2015b; Stoessel, 2012). Esto se debe principalmente a que, hasta hace pocos años, el límite temporal de la evidencia de ocupación humana en el área no excedía los 3000 años AP. Sin embargo, el hallazgo de nuevos sitios con cronologías del Holoceno medio (ca. 6300-4100 años AP; Martínez, 2017) permitió ampliar la profundidad temporal de las ocupaciones y, en consecuencia, profundizar en el conocimiento de distintos aspectos de la organización de los grupos cazadores-recolectores que habitaron el área durante este periodo (Carden y Martínez, 2014; Flensborg, Martínez y Tessone, 2018; Martínez y Flensborg, 2018; Santos Valero, 2017; Stoessel, 2015). Los sitios con esta cronología se ubican tanto en el sector costero (Cantera de Rodados Villalonga y Tres Bonetes 1; Figura 1) como en el interior del área (La Modesta y Loma de los Morteros; Figura 1). Sin embargo, solo estos últimos cuentan con material zooarqueológico. Dichos sitios están emplazados en contextos de dunas, en los que el material arqueológico está distribuido mayormente en las superficies de hoyadas de deflación (Martínez et al., 2017a). Entre los especímenes faunísticos recuperados se destaca una gran abundancia de restos de peces, específicamente de la especie fluvial Percichthys trucha que habría sido aprovechada como parte de la subsistencia de los grupos humanos (Stoessel, 2015). A esto se suma una elevada frecuencia de especímenes óseos correspondientes a otros taxa de vertebrados de pequeño tamaño (e. g., roedores, armadillos, aves) que comenzaron a ser estudiados recientemente.

En este trabajo se presentan los resultados obtenidos del análisis de los restos de fauna menor (a excepción de los peces) recuperados en el sitio La Modesta (ca. 5900-5600 años AP). Este estudio tiene como objetivo comprender las historias tafonómicas de los conjuntos óseos con el fin de determinar el origen del ingreso de los distintos taxa al sitio y evaluar cuáles fueron aprovechados por las poblaciones humanas. En otra escala de análisis, esta información, sumada a la ya generada para las especies de tamaño mayor y peces en este sitio (Martínez et al., 2014; Stoessel, 2015), contribuirá a comprender las historias de formación del registro arqueológico en un ambiente de dunas y permitirá profundizar en el conocimiento de la subsistencia durante el Holoceno medio, periodo para el cual los estudios faunísticos en la transición pampeano patagónica oriental son aún escasos.

\section{La Modesta: aspectos generales del sitio}

El sitio La Modesta (LMO) se ubica en el partido de Patagones (provincia de Buenos Aires), a los $39^{\circ} 40^{\prime} 57,4^{\prime \prime}$ ' y $62^{\circ} 50^{\prime} 5,8^{\prime \prime} \mathrm{O}$. Está localizado a $900 \mathrm{~m}$ de un paleocauce 


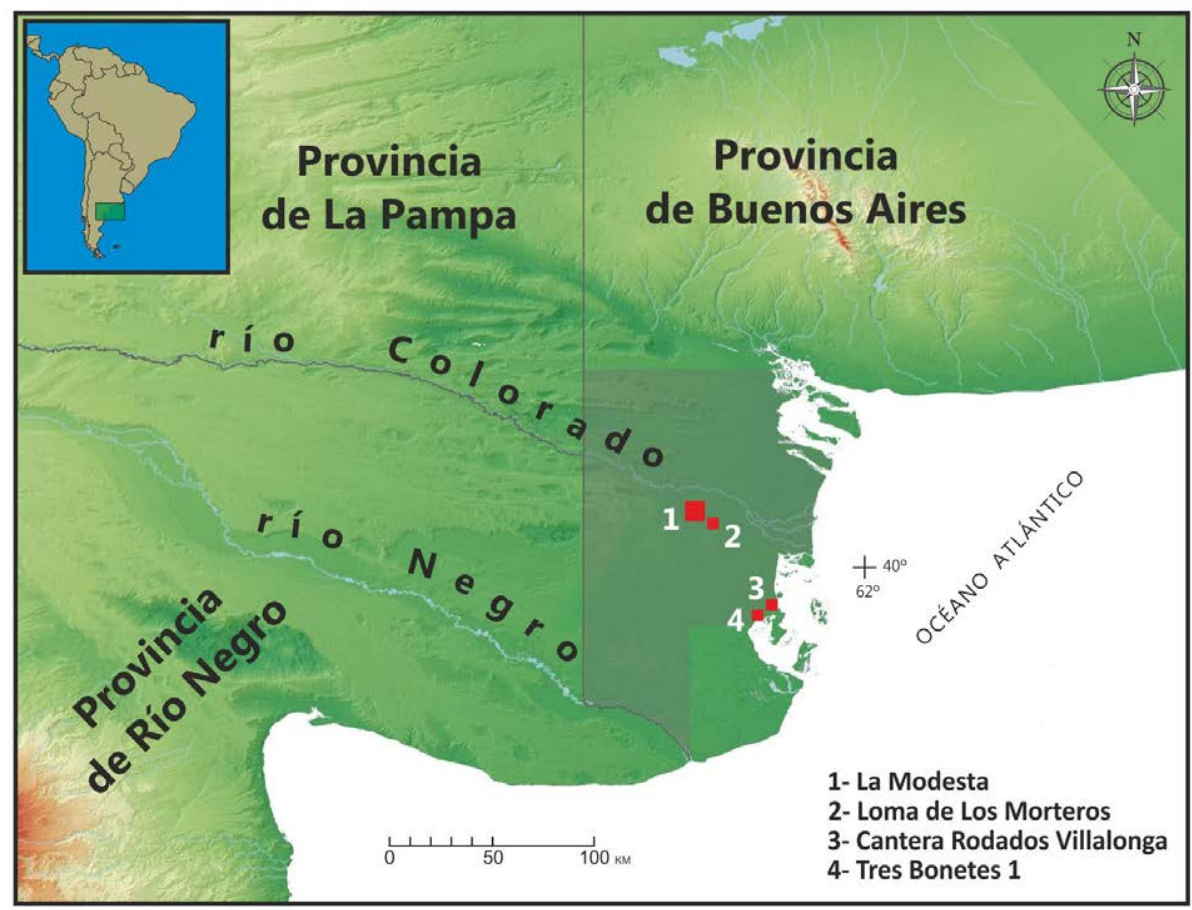

Figura 1. Ubicación geográfica del sitio La Modesta y de otros sitios del área con cronologías del Holoceno medio mencionados en el texto.

del río Colorado y a aproximadamente $60 \mathrm{~km}$ de la costa Atlántica (Figura 1). Los materiales se encuentran en su mayoría distribuidos sobre la superficie de una hoyada de deflación de alrededor de $5.000 \mathrm{~m}^{2}$ (Figura 2).

Los trabajos de campo tuvieron lugar entre los años 2013 y 2016. En una primera etapa se llevaron a cabo recolecciones superficiales sistemáticas a través de 20 transectas de 2 $\mathrm{m}$ de ancho y longitud variable en función de la topografía de la hoyada (Figura 2A-B). Con posterioridad, en una segunda etapa, se realizaron 40 muestreos sub-superficiales de $1 \mathrm{~m}^{2}$ distribuidos de manera aleatoria (Figura 2A-C). Asimismo, se excavaron 21 cuadrículas de $1,5 \mathrm{~m} \times 1,5 \mathrm{~m}$ en distintos sectores de la duna que rodea a la hoyada (Figura 2A-D). A través de estas excavaciones se cubrió una superficie de $47,25 \mathrm{~m}^{2}$. Los sucesivos trabajos de campo, permitieron recuperar una gran diversidad de materiales, la mayor parte de los cuales corresponden a artefactos líticos y, en frecuencias menores, restos óseos humanos y faunísticos, material malacológico y cáscaras de huevo de Rheidae, algunas de ellas grabadas (Carden y Martínez, 2014; Martínez et al., 2014; Santos Valero, 2017; Stoessel, 2015).

En los sectores excavados, los estudios geoarqueológicos permitieron distinguir cuatro unidades estratigráficas que corresponden en su totalidad a depósitos de origen eólico (Figura 3). Entre la Unidad 2 y $3 \mathrm{~A}$ se observa una discordancia a partir de la cual se identificó la presencia de material arqueológico. En general, éste se presenta en baja frecuencia y es de tamaño muy pequeño (i.e. microlascas, fragmentos óseos menores a $2 \mathrm{~cm}$ ). La frecuencia de estos materiales comienza a disminuir en la parte inferior de la Unidad 3B para finalmente desaparecer hacia el techo de la Unidad 4. Sobre la base de este patrón de distribución vertical se delimitó un depósito arqueológico relacionado con un horizonte A de suelo enterrado (Unidad 3A - 2ACb1; Martínez et al., 2017b). Con el objetivo de conocer la cronología de este depósito se enviaron a datar por AMS tres muestras óseas, sin embargo, no se pudo recuperar colágeno de ninguna de ellas. Ante esta situación se está llevando 


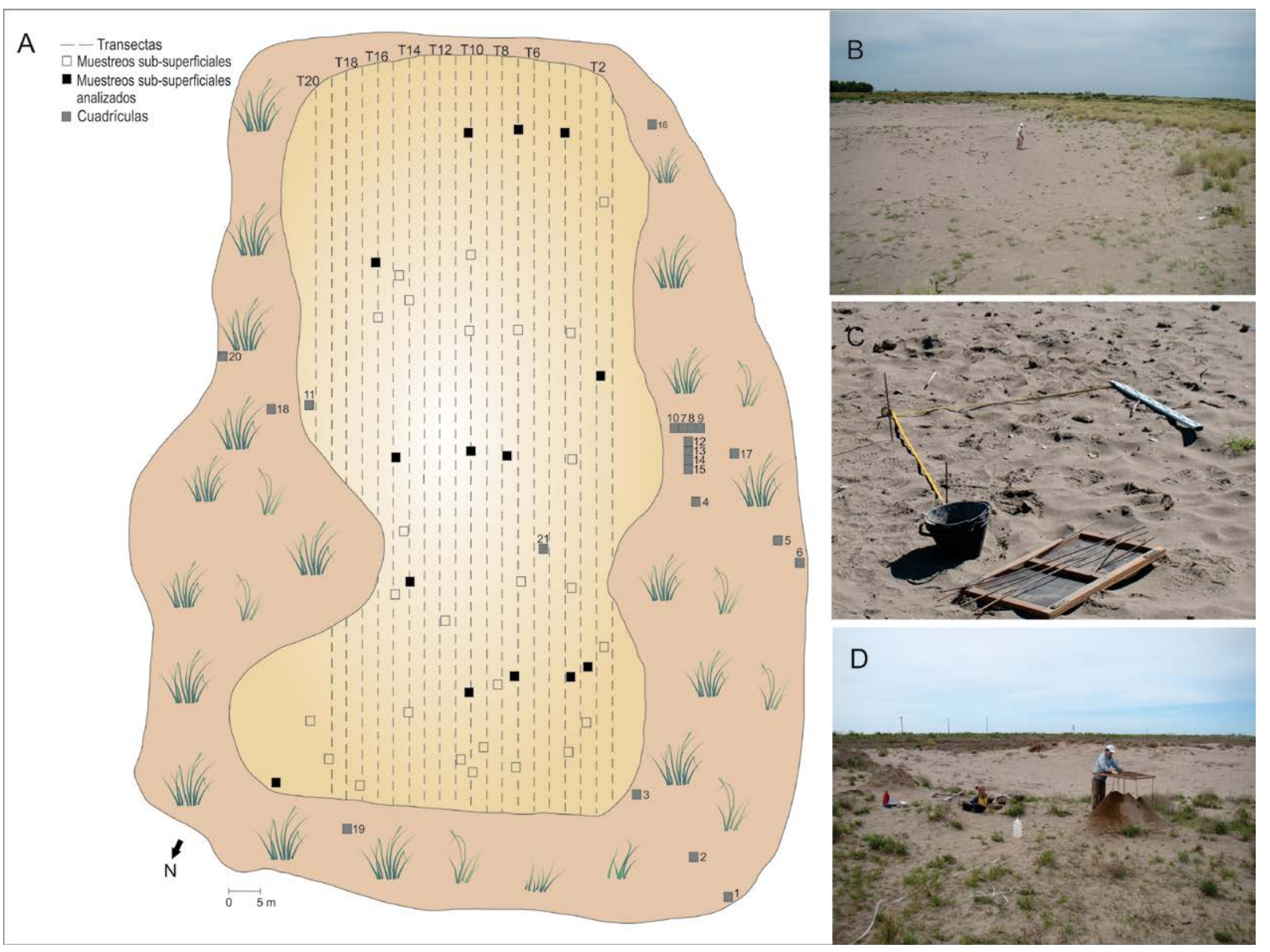

Figura 2. Sitio La Modesta. A) Planta de la hoyada en la que se observa la distribución de las transectas, muestreos y excavaciones realizados en las diversas etapas de trabajo de campo. Se mencionan solo las transectas analizadas en este trabajo; B) foto de la hoyada y demarcación de transectas; $C$ ) imagen donde se muestra el planteo de los muestreos sub-superficiales; $D$ ) foto de la excavación de una de las cuadrículas sobre el médano.

a cabo un programa de dataciones OSL (Martínez et al., 2017a, 2017b), con el fin de conocer las edades de los estratos que contienen los materiales. No obstante, fue posible obtener cuatro fechados radiocarbónicos de restos óseos recuperados de superficie, los cuales comprenden el rango de ca. 5900-5600 años AP. Uno de ellos proviene de un desecho de fractura helicoidal sobre fémur de Lama guanicoe el cual arrojó una edad de $5641 \pm 66$ años AP (Carden y Martínez, 2014). Un segundo fechado se obtuvo de una hemimaxila de Myocastor coypus el cual proporcionó una edad de $5846 \pm 51$ años AP (Martínez, 2017). Los dos restantes fueron realizados sobre tibias de dos individuos de Homo sapiens que dieron edades de $5890 \pm 52$ años AP y $5904 \pm 37$ años AP (Martínez, 2017). De esta manera, se observa una buena correlación entre las edades obtenidas de los materiales de superficie, permitiendo ubicar cronológicamente las ocupaciones humanas del sitio en el Holoceno medio (Martínez et al., 2017b).

\section{Materiales y metodología de análisis}

Para este trabajo se analizó una muestra del total de restos de fauna menor recuperados en el sitio, tanto en superficie como en estratigrafía. El material analizado de superficie proviene de nueve transectas y 14 muestreos sub-superficiales, en tanto los restos de excavación proceden de cuatro cuadrículas (1 a 4; Figura 2). 


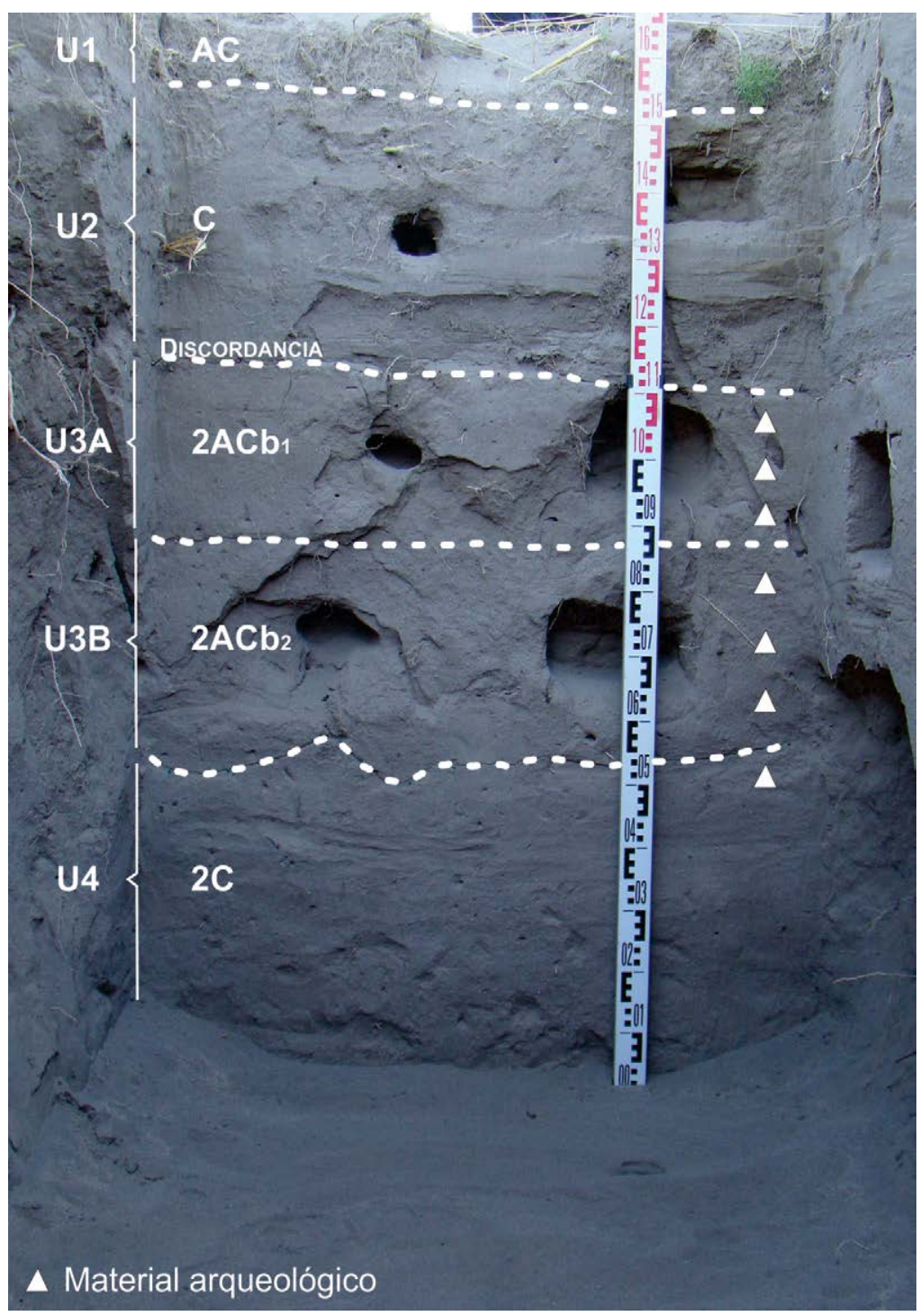

Figura 3. Secuencia estratigráfica del sitio La Modesta.

Se considera fauna menor a todos aquellos vertebrados que no exceden los $15 \mathrm{~kg}$ de peso. Debido a que este concepto involucra un amplio rango de peso se decidió subdividir dicha categoría considerando las divisiones empleadas por Salemme, Escosteguy y Frontini (2012): micro (menos de $1 \mathrm{~kg}$ ); pequeño (entre $1 \mathrm{~kg}$ y $3 \mathrm{~kg}$ ), mediano-pequeño (entre $3 \mathrm{~kg}$ y $15 \mathrm{~kg}$ ). En el caso de las aves, se empleó la clasificación de Giardina (2010) considerando aves medianas (aves de ambientes acuáticos, tinámidos y aves rapaces) $\mathrm{y}$ aves pequeñas (e.g., Familia Columbidae y Orden Passeriformes).

Para el análisis faunístico del conjunto óseo se llevó a cabo la identificación anatómica y taxonómica de los restos mediante el empleo de muestras comparativas de la Colección Osteológica del INCUAPA-CONICET, FACSO-UNICEN, la Colección Osteológica de Aves de la División Paleontología de Vertebrados del Museo de Ciencias Naturales de La Plata, FCNyM-UNLP y la Colección Osteológica de la División Ornitología del Museo Argentino de Ciencia Naturales. La cuantificación del material se realizó a partir del empleo de medidas de abundancia taxonómica (i.e. MNI, NISP) y anatómica (i.e. MNE, Ri) (Andrews, 1990; Lyman, 1994, 2008). La abundancia relativa (Ri) se calculó empleando el índice formulado por Andrews (1990): Ri = MNEi/(Ei x MNI) x 100, 
donde MNEi es el número mínimo del elemento i en la muestra y Ei es el número esperado de ese elemento esquelético en un individuo. Asimismo, se aplicaron índices para evaluar la supervivencia de determinados elementos esqueletarios y segmentos anatómicos de algunos de los taxa identificados (i.e. roedores; Andrews, 1990). Uno de ellos compara la representación del esqueleto postcraneal respecto al craneal (PCR/ CR), en tanto el otro considera la proporción entre elementos distales (zeugopodio) y proximales (estilopodio) de los miembros (Z/E) (Andrews, 1990).

En el análisis de las modificaciones naturales y antrópicas se relevaron las siguientes variables: meteorización (Andrews, 1990; Behrensmeyer, 1978; Behrensmeyer, Stayton y Chapman, 2003), deterioro químico (Gutiérrez, 2004), acción de raíces (Fernández-Jalvo y Andrews, 2016), depositación química (carbonato y manganeso; Gutiérrez, 2004), pisoteo (Andrews, 1990; Fernández-Jalvo y Andrews, 2016), marcas de dientes de carnívoros y roedores (Binford, 1981), abrasión geológica (Fernández-Jalvo y Andrews, 2016), digestión (Bochenski y Tomek, 1997; Fernández, Montalvo, Fernández-Jalvo, Andrews y López, 2017; Pinto Llona y Andrews, 1999), huellas de corte (Fisher, 1995) y alteración térmica (Frontini y Vecchi, 2014; Pardiñas, 1999). Dichas variables fueron relevadas bajo lupa estereoscópica binocular a 20X y 40X (MOTIC Modelo M39 y Hokenn Optik Modelo ZTX E ZOOM 40X). El registro fotográfico se realizó mediante el empleo de un microscopio digital DinoLite y un microscopio estereoscópico LEICA S6D. El análisis de las variables tafonómicas se realizó sobre los restos que fueron determinados a nivel anatómico y taxonómico a excepción de las placas dérmicas. Sobre éstas solo se relevaron aquellas variables vinculadas con las modificaciones antrópicas (huellas de corte y alteración térmica).

En el análisis de las fracturas se distinguieron aquellas de origen post-depositacional y las realizadas sobre hueso fresco (Johnson, 1985). Para evaluar la intensidad de la fragmentación de los conjuntos se calculó el porcentaje de completitud de los elementos (C\%), comparando el número de elementos completos con el número total de fragmentos de un tipo particular de hueso (Bochenski, 2005).

\section{Resultados}

\section{Composición del conjunto de fauna menor}

El análisis faunístico se realizó sobre un total de 4.965 restos óseos, recuperados tanto en superficie como en estratigrafía. El conjunto proveniente de superficie está compuesto por 4.584 restos de los cuales $89,9 \%(n=4.119)$ pudieron ser asignados a algún nivel de determinación anatómica y taxonómica (Tabla 1). Entre las categorías taxonómicas más inclusivas que se pudieron identificar, los mamíferos son los que registran la mayor frecuencia $(80,2 \% ; \mathrm{n}=3.302)$ y dentro de estos se destacan los roedores con $c a .61 \%(\mathrm{n}=$ $2.524)$, seguido por los armadillos con $13 \%(n=536)$. En bajo porcentaje se encuentran representados los marsupiales y carnívoros $(0,2 \% ; n=8$ y $0,1 \% ; n=3$, respectivamente; Tabla 1). En orden decreciente, a los mamíferos les siguen en frecuencia las aves, las cuales constituyen el $8,4 \%(n=344)$ del conjunto y los reptiles $(c a .1 \% ; n=47)$ y anfibios $(0,3 \% ; \mathrm{n}=12)$ en proporciones menores (Tabla 1$)$.

El conjunto procedente de excavación está compuesto por un número menor de restos $(n=381)$. Entre estos el $77,7 \%(n=296)$ pudo asignarse a alguna categoría taxonómica y anatómica (Tabla 1). Al igual que en el conjunto de superficie, la Clase Mammalia es la que presenta la mayor frecuencia $(71,6 \% ; n=212)$, destacándose al interior de ésta, los roedores con ca. $41 \%(\mathrm{n}=122)$, seguido por los armadillos con el ca. $27 \%$ $(n=79)$ y los marsupiales representados por un único resto. En orden decreciente, a los mamíferos le siguen las aves ( $c a .6 \% ; n=17)$, los anfibios $(1 \% ; n=3)$ y los reptiles $(0,3 \% ; \mathrm{n}=1)$ en frecuencias menores (Tabla 1$)$. 


\begin{tabular}{|c|c|c|c|c|c|}
\hline & & \multicolumn{2}{|c|}{ Superficie } & \multicolumn{2}{|c|}{ Excavación } \\
\hline & & NISP & NISP\% & NISP & NISP\% \\
\hline \multicolumn{2}{|l|}{ Anfibios } & 12 & 0,3 & 3 & 1 \\
\hline \multicolumn{2}{|l|}{ Reptiles } & 47 & 1,1 & 1 & 0,3 \\
\hline \multicolumn{2}{|l|}{ Aves } & 344 & 8,4 & 17 & 5,7 \\
\hline Mamíferos & $\begin{array}{l}\text { Mediano pequeño indeterminado (3-15 kg) } \\
\text { Pequeño indeterminado (1-3 kg) } \\
\text { Roedores } \\
\text { Armadillos } \\
\text { Carnívoros } \\
\text { Marsupiales }\end{array}$ & $\begin{array}{c}95 \\
136 \\
2.524 \\
536 \\
3 \\
8\end{array}$ & $\begin{array}{l}2,3 \\
3,3 \\
61,3 \\
13 \\
0,1 \\
0,2\end{array}$ & $\begin{array}{c}9 \\
1 \\
122 \\
79 \\
0 \\
1\end{array}$ & $\begin{array}{c}3 \\
0,3 \\
41,2 \\
26,7 \\
0 \\
0,3\end{array}$ \\
\hline \multicolumn{2}{|c|}{ Microvertebrados indeterminados ( $<1 \mathrm{~kg}$ ) } & 414 & 10,1 & 63 & 21,3 \\
\hline \multicolumn{2}{|l|}{ Total } & 4.119 & 100 & 296 & 100 \\
\hline \multicolumn{2}{|c|}{ Número de restos óseos indeterminados } & 465 & - & 85 & - \\
\hline
\end{tabular}

Tabla 1. Composición taxonómica del conjunto de fauna menor recuperado en superficie y en excavación. Expresada en NISP y NISP\%.

\section{Análisis de los taxa representados}

\section{Los anfibios}

Los anfibios están representados por un bajo número de restos tanto en superficie como en estratigrafía (Tabla 1). En el primero de los casos, se identificaron nueve elementos asignados al Orden Anura y tres al Género $c f$. Cerathrophys. Estos últimos corresponden a fragmentos de cráneo, en tanto los elementos identificados a nivel de Orden corresponden casi en su totalidad a elementos postcraneales. En cuanto a las modificaciones de las superficies óseas se observó que los restos se encuentran preferentemente abradidos por erosión eólica y en seis casos se registró descamación del tejido cortical ${ }^{1}$. En tres restos se identificaron tinciones de manganeso, mientras que, evidencias de meteorización (i.e. pequeños agrietamientos), marcas de raíces y depositaciones de carbonato de calcio, se registraron en un solo espécimen. Además, un fragmento de ilion se encontró termoalterado (quemado). En cuanto al grado de fragmentación, a excepción de una tibio-fíbula y una escápula que se recuperaron completas, el resto de los especímenes presentan algún grado de rotura asociado a causas post-depositacionales.

En el conjunto que procede de excavación, se recuperaron tres especímenes de Anura (ilion, escápula y húmero). Estos mostraron presencia de carbonato de calcio, acción de raíces y deterioro químico. Ninguno de ellos se recuperó en estado completo.

\section{Los reptiles}

En el conjunto de superficie los reptiles están representados mayormente por ofidios $(n=45)$, entre los cuales el 51,1\% $(n=23)$ pudo atribuirse a la Familia Colubridae. Asimismo, se registró un espécimen de Tupinambis sp. En todos los casos, los elementos anatómicos corresponden a vértebras. El análisis de las variables tafonómicas mostró que el $61,7 \%(n=29)$ del conjunto presentó las superficies pulidas como consecuencia de la abrasión eólica. En un 46,8\% $(\mathrm{n}=22)$ se registró descamación y en el 25,5\% $(\mathrm{n}=12)$ se detectaron evidencias de meteorización (i.e. pequeños agrietamientos). Las tinciones de manganeso y depositaciones de carbonato de calcio se presentaron en iguales frecuencias $(21,3 \% ; \mathrm{n}=10)$. Solo una vértebra de colúbrido se encontró
1. Esta modificación se caracteriza por la exfoliación superficial del tejido cortical sin presencia de agrietamiento previo (FernándezJalvo et al., 1998; Fernández-Jalvo y Andrews, 2016). En un principio y en términos operativos, se la distingue de la meteorización ya que se considera que varios procesos en conjunto habrían dado lugar a la generación de dicho efecto (ver apartado Interpretación del conjunto faunístico). El relevamiento de esta variable se consideró en el análisis de las superficies óseas de los restos de todos los taxa identificados. 
quemada. Con respecto a la muestra de excavación, se recuperó una vértebra de ofidio con la superficie cubierta de carbonato de calcio.

\section{Las aves}

El conjunto avifaunístico de la muestra de superficie está compuesto por 344 especímenes que en su mayoría $(83,7 \%)$ corresponden a especies de tamaño mediano (Tabla 2). Entre aquellas que pudieron ser asignadas a categorías taxonómicas más precisas se destacan las familias Rallidae (14,5\%) y Tinamidae (7,8\%). Para la primera de éstas, se pudo identificar la presencia de Fulica leucoptera con un MNI de 2. Los especímenes determinados como Fulica sp. podrían corresponder a esta especie y, en menor medida, a un taxón de mayor tamaño como Fulica armillata. La elevada fragmentación impidió, en estos casos, precisar la determinación taxonómica. Entre los tinámidos, se estableció la presencia de dos individuos de Eudromia elegans y uno de Nothura sp. Asimismo, se identificaron escasos elementos correspondientes a Anseriformes, Falconiformes y Podiceps sp. (Tabla 2).

En cuanto a la representación de partes esqueletarias, si bien el promedio de la abundancia relativa es bajo (27,5\%), la mayor parte de los elementos anatómicos se encuentran presentes. Entre estos predominan coracoides $(97,2 \% ; \mathrm{MNE}=35)$, esternón $(72,2 \% ; \mathrm{MNE}=13)$, tibiotarso $(69,4 \% ; \mathrm{MNE}=25)$ y tarsometatarso $(63,9 \% ; \mathrm{MNE}=23)$. Con frecuencias menores le siguen el sinsacro $(44,4 \% ; \mathrm{MNE}=8)$, la escápula $(38,9 \%$; $\mathrm{MNE}$ $=14)$, el radio $(33,3 \% ; M N E=12)$ y el húmero y fémur con valores similares $(30,6 \%$; $\mathrm{MNE}=11$ ). Los restantes elementos se encuentran representados con porcentajes más bajos (i.e. cráneo, vértebras, pelvis y huesos del autopodio), mientras que las costillas, fúrcula y mandíbula están ausentes.

En lo que respecta a las modificaciones óseas, se observa que los especímenes fueron afectados principalmente por abrasión eólica $(63,7 \% ; n=219)$. La acción de la misma se vio reflejada a través del pulido homogéneo de las superficies óseas producto del cual los especímenes presentan aspecto brilloso y textura suave. Asimismo, en algunos casos se observa el esculpido de los restos producto del impacto de las partículas sedimentarias sobre el hueso. Las depositaciones de óxido de manganeso también se presentan en importante frecuencia $(41,9 \% ; n=144)$, aunque la mayor parte de los restos cuenta con un bajo porcentaje de la superficie afectada (pequeñas manchas distribuidas azarosamente). La meteorización es otra de las variables que ha afectado a los especímenes óseos. Si bien la mayoría de los restos se encuentra en el estadio 0 $(76,7 \%)$, un porcentaje importante $(20,9 \% ; \mathrm{n}=72)$ corresponde al estadio 1 . En menor frecuencia se registraron especímenes en los estadios 2 y 3 (en torno al $1 \% ; n=5$ y 3 , respectivamente). En el 27,6\% $(n=95)$ de los restos se observó el descamado del tejido cortical (Figura 4A). En algunos casos, los remanentes del mismo se encuentran asociados a concreciones de sedimento y/o carbonato de calcio. Este último se registró en el $23 \%(n=79)$ de los especímenes óseos. Se observó una baja incidencia de la acción de las raíces y del deterioro químico (entre aproximadamente el 8\% y 7\%; $\mathrm{n}=28$ y 23 , respectivamente). En muy bajos porcentajes se determinó la presencia de marcas de roedores $(3,2 \% ; \mathrm{n}=11)$ y de pisoteo $(0,3 \% ; \mathrm{n}=1)$. Las marcas de carnívoros se encuentran ausentes. Asimismo, las modificaciones producidas por digestión no son claras. En este sentido, se hallaron escasos restos que muestran exposición del tejido trabecular en las epífisis, acompañado de un pulido y redondeo de la superficie $(1,4 \% ; \mathrm{n}=5)$. Sin embargo, estas características también pueden ser consecuencia de la acción conjunta de la abrasión sedimentaria y la meteorización. Esto mismo ocurre en el caso de las fracturas entre las cuales aproximadamente el 18\% presenta superficies pulidas con ángulos redondeados y resulta difícil distinguir si son producto de la acción digestiva o de la abrasión. 


\begin{tabular}{|c|c|c|c|c|c|c|c|}
\hline \multirow{2}{*}{ Taxa } & \multirow{2}{*}{$\begin{array}{l}\text { Nombre } \\
\text { vernáculo }\end{array}$} & \multicolumn{3}{|c|}{ Superficie } & \multicolumn{3}{|c|}{ Excavación } \\
\hline & & NISP & NISP\% & MNI & NISP & NISP\% & MNI \\
\hline Aves indet. & - & 55 & 16 & NA & - & - & - \\
\hline Aves pequeña indet. & - & 1 & 0,3 & 1 & - & - & - \\
\hline Aves mediana indet. & - & 207 & 60,2 & NA & 15 & 88,2 & NA \\
\hline Anseriformes & - & 2 & 0,6 & 1 & - & - & - \\
\hline Falconiformes & - & 1 & 0,3 & 1 & - & - & - \\
\hline Gruiformes & - & - & - & - & - & - & - \\
\hline Rallidae & - & 2 & 0,6 & NA & - & - & - \\
\hline Fulica sp. & Gallareta & 44 & 12,8 & 11 & 2 & 11,8 & 2 \\
\hline Fulica leucoptera & Gallareta chica & 4 & 1,2 & $(2)^{*}$ & - & - & - \\
\hline Podicipediformes & - & - & - & - & - & - & - \\
\hline Podecipedidae & - & - & - & - & - & - & - \\
\hline Podiceps sp. & Macá & 1 & 0,3 & 1 & - & - & - \\
\hline Tinamiformes & - & - & - & - & - & - & - \\
\hline Tinamidae & - & 14 & 4,1 & NA & - & - & - \\
\hline Eudromia elegans & Martineta & 12 & 3,5 & 2 & - & - & - \\
\hline Nothura sp. & Inambú & 1 & 0,3 & 1 & - & - & - \\
\hline Total & - & 344 & 100 & 18 & 17 & 100 & 2 \\
\hline
\end{tabular}

Tabla 2. Composición taxonómica del conjunto de aves de superficie y excavación.

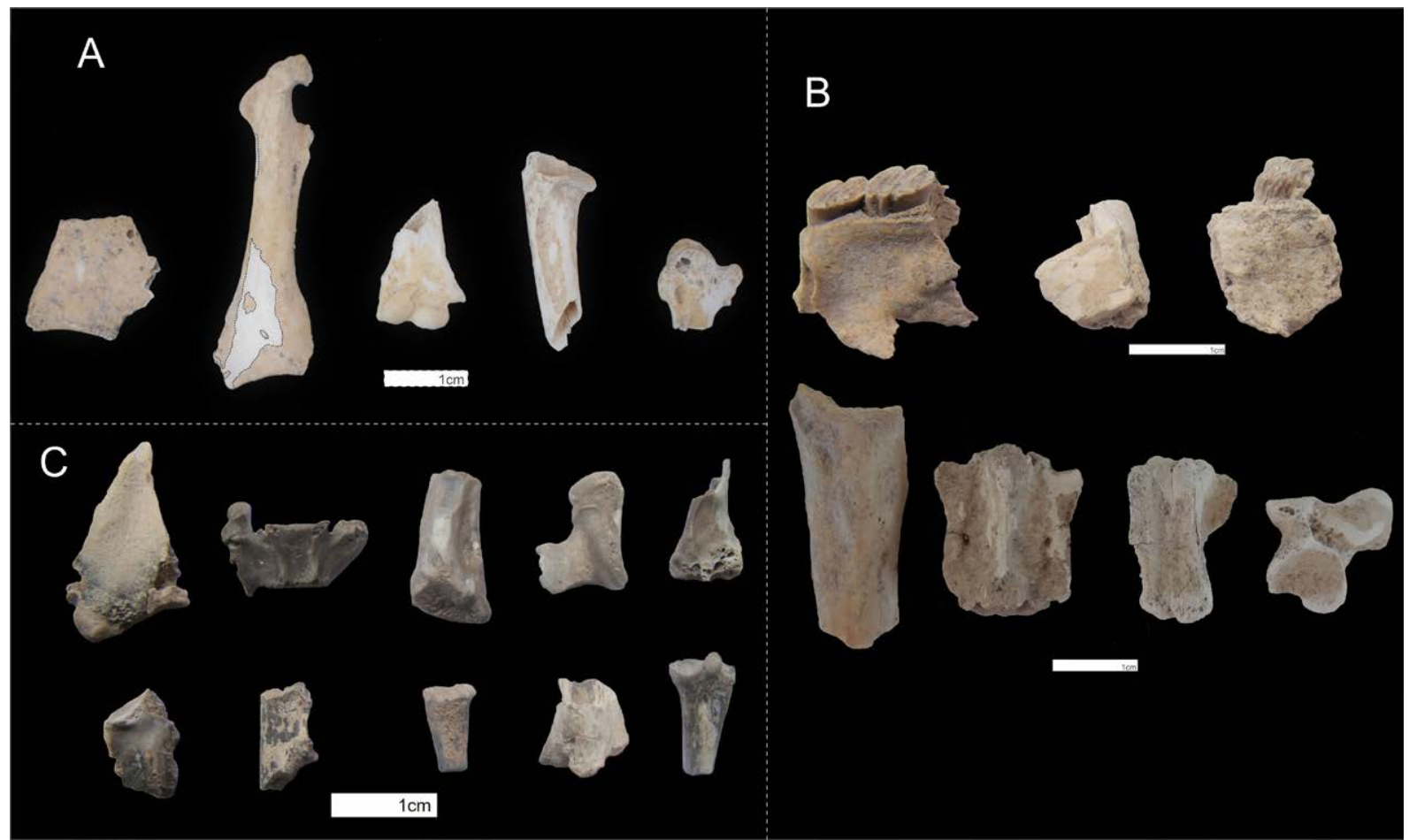

Figura 4. A) Restos óseos de aves del conjunto de superficie con diferentes grados de descamación del tejido cortical; B) restos óseos de M. coypus del conjunto de superficie con diferentes grados de descamación del tejido cortical; C) restos óseos de aves, M. coypus y armadillos del conjunto de superficie con evidencias de termoalteración. 
En cuanto a las modificaciones de origen antrópico, se identificó una huella de corte en un fragmento de esternón de un ave mediana indeterminada ubicada en la cara externa, cercana a la superficie articular con las costillas (Figura 5). Sumado a esto, se han identificado evidencias de alteración térmica en 13,9\% $(n=48)$ de los restos correspondientes a diversos elementos del esqueleto, siendo vértebras y falanges los más afectados. Entre estos, $62,5 \%(n=30)$ se encuentran calcinados, $31,2 \%(n=15)$ quemados y $6,2 \%(n=3)$ carbonizados. En todos los casos se observa una alteración homogénea y completa de la superficie. Por último, se destaca que gran parte de los especímenes presenta algún grado de fragmentación, siendo el porcentaje de completitud bajo $(13,1 \%)$. La mayor parte de las fracturas presenta bordes agudos y ásperos $(c a .81 \% ; \mathrm{n}=241)$ por lo que se les atribuye un origen post-depositacional (Bochenski y Tomek, 1997).

Con respecto al conjunto avifaunístico proveniente de excavación el número de restos es bajo $(\mathrm{n}=17)$ y corresponden mayormente a especímenes de aves medianas indeterminadas $(88,2 \%)$. Dos restos (coracoides proximales) pudieron ser asignados a Fulica sp. a partir de los cuales se estimó un MNI de 2 (Tabla 2). En cuanto a la representación anatómica, a partir del cálculo de la abundancia relativa, se observa que los especímenes corresponden, en mayor medida, a elementos del esqueleto apendicular y están presentes en frecuencias similares (50\%): coracoides, húmero y radio, del miembro anterior y fémur, tibiotarso, fíbula y tarsometatarso, del miembro posterior. La principal modificación observada fue la presencia de depositaciones de carbonato de calcio $(76,5 \% ; n=13)$. En menor frecuencia se registraron tinciones de manganeso $(23,5 \% ; n=4)$ e improntas de raíces $(17,6 \% ; \mathrm{n}=3)$. Asimismo, se recuperó un espécimen con deterioro químico $(5,9 \%)$ y dos $(11,8 \%)$ con evidencias de termoalteración (quemado). La totalidad de los especímenes, a excepción de una falange, registra algún grado de fragmentación, atribuible en mayor medida a causas post-depositacionales.

\section{Los roedores}

Los roedores constituyen la categoría taxonómica más abundante en los conjuntos provenientes tanto de superficie como de excavación. En el primero de los casos, se cuenta con 2.524 restos. Los roedores caviomorfos son los que presentan la mayor frecuencia (76,1\%). Entre ellos predomina Ctenomys sp. (ca. 56\%) cuyo MNI estimado es de 127 individuos. Le sigue en frecuencia la Familia Caviidae $(13,1 \%)$ representada por seis individuos de Galea leucoblephara, seis de Microcavia australis y un ejemplar de Dolichotis patagonum. Asimismo, se identificó la presencia de nueve individuos de Myocastor coypus (6,5\%; Tabla 3). En menor proporción se registró la presencia de roedores cricétidos $(1,6 \%)$, representados principalmente por Reithrodon auritus, para el cual se calculó un MNI de seis, seguido por Holochilus vulpinus, Akodon sp. y Eligmodontia sp. representados cada uno de estos por un individuo (Tabla 3). Un considerable número de restos fue atribuido a la categoría Rodentia indeterminada (ca. 22\%; Tabla 3), los cuales, en general, corresponden a elementos del postcráneo

2. Cabe aclarar que, en general, las determinaciones taxonómicas a nivel de especie se realizaron a partir de elementos craneales, principalmente molares. que no pudieron ser identificados a un nivel más específico ${ }^{2}$ pero que por su tamaño corresponden a especies con pesos menores a $1 \mathrm{~kg}$.

El conjunto de excavación arrojó un total de 122 restos de roedores y las tendencias observadas en relación con las frecuencias de los taxa identificados es similar a la descripta para el conjunto de superficie, siendo los roedores caviomorfos los mejor representados (Tabla 3). En este sentido, en orden decreciente, los principales taxones recuperados son Ctenomys sp. (ca. $30 \%$; MNI $=5)$, Caviidae $(16,4 \%)$ representada por una única especie de cuis $(M$. australis; $\mathrm{MNI}=1)$ y $M$. coypus $(c a .6 \% ; \mathrm{MNI}=1)$. Entre los roedores cricétidos se identificó la presencia de $R$. auritus ( ca. 4\%; $\mathrm{MNI}=3$ ). Al igual que en el conjunto procedente de superficie, un importante porcentaje de la muestra corresponde a restos asignados a nivel de orden (Tabla 3). 


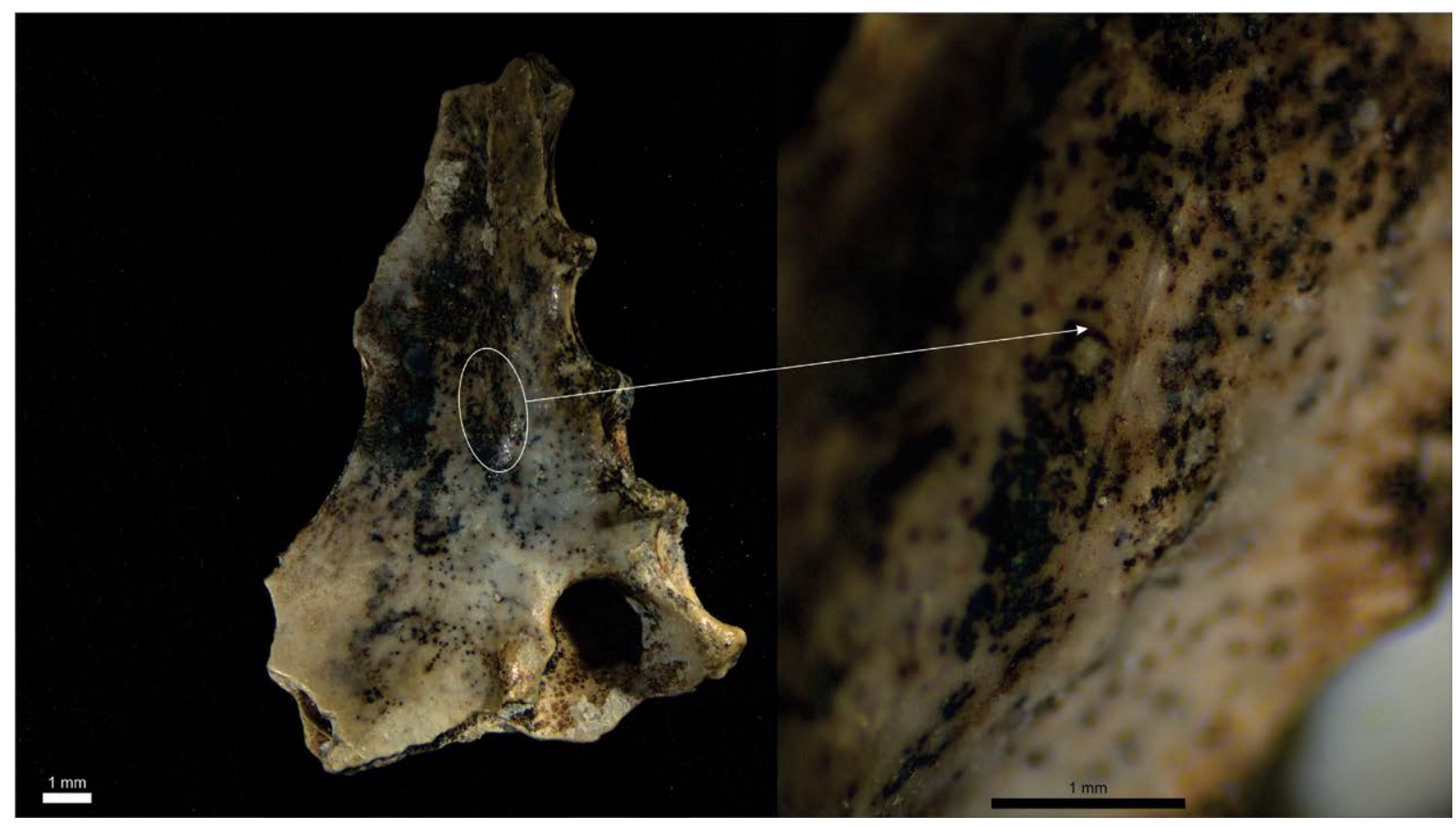

Figura 5. Fragmento de esternón de ave mediana indeterminada y detalle de la huella de corte.

\begin{tabular}{|c|c|c|c|c|c|c|c|}
\hline \multirow{2}{*}{ Taxa } & \multirow{2}{*}{$\begin{array}{c}\text { Nombre } \\
\text { vernáculo }\end{array}$} & \multicolumn{3}{|c|}{ Superficie } & \multicolumn{3}{|c|}{ Excavación } \\
\hline & & NISP & NISP\% & MNI & NISP & NISP\% & MNI \\
\hline Rodentia indet. & - & 561 & 22,2 & NA & 50 & 41 & NA \\
\hline Caviomorpha & - & - & - & - & - & - & - \\
\hline Myocastoridae & - & - & - & - & - & - & \\
\hline Myocastor coypus & Coipo & 164 & 6,5 & 9 & 7 & 5,7 & 1 \\
\hline Caviidae & - & 280 & 11,1 & NA & 18 & 14,8 & NA \\
\hline Dolichotis patagonum & Mara & 3 & 0,1 & 1 & - & - & - \\
\hline Galea leucoblephara & Cuis común & 24 & 1 & 6 & - & - & - \\
\hline Microcavia australis & Cuis chico & 24 & 1 & 6 & 2 & 1,6 & 1 \\
\hline Ctenomyidae & - & & & & & & \\
\hline Ctenomys sp. & Tuco-tuco & 1.427 & 56,5 & 127 & 37 & 30,3 & 5 \\
\hline Myomorpha & - & & & & & & \\
\hline Cricetidae & - & 18 & 0,7 & NA & 3 & 2,5 & NA \\
\hline Holochilus vulpinus & Rata nutria & 2 & 0,1 & 1 & - & - & - \\
\hline Reithrodon auritus & Rata conejo & 19 & 0,8 & 6 & 5 & 4,1 & 3 \\
\hline Akodon sp. & Ratón de campo & 1 & 0,04 & 1 & - & - & - \\
\hline Eligmodontia sp. & Laucha colilarga & 1 & 0,04 & 1 & - & - & - \\
\hline Total & - & 25.24 & 100 & 158 & 122 & 100 & 10 \\
\hline
\end{tabular}

Tabla 3. Composición taxonómica del conjunto de roedores de superficie y excavación. 


\section{Roedores $>1 \mathrm{~kg}$}

En cuanto a la abundancia de partes anatómicas en el conjunto de superficie, $M$. coypus está representado por todo el esqueleto (a excepción de algunos elementos como costilla y fíbula), aunque en escasa frecuencia $(\mathrm{Ri}=19,2 \%)$. A excepción de la mandíbula, los elementos anatómicos presentan valores por debajo del $50 \%$. Por su parte $D$. patagonum se halla representada por un fragmento de maxila, un molar aislado y una falange.

A partir del análisis de las modificaciones de las superficies óseas, se observa que gran parte del conjunto está afectado por la abrasión eólica $(68,9 \% ; n=113)$. La acción de la misma se reconoció a partir del pulido y el esculpido de las superficies óseas y del redondeo de los bordes anatómicos. Un elevado porcentaje de restos presentó evidencias de meteorización, las cuales se concentran mayormente en el estadio 1 $(31,7 \% ; \mathrm{n}=52)$. En frecuencias menores se identificaron especímenes en el estadio $2(9,1 \% ; n=15)$ y $3(7,3 \% ; n=12)$. Las tinciones de manganeso constituyen otra de las variables que se registró en un elevado número de casos $(43,9 \% ; \mathrm{n}=72)$ aunque ca. $41 \%$ de los restos muestran un escaso porcentaje de la superficie ósea afectada, lo que indica una baja incidencia de este efecto. Un importante número de restos de $M$. coypus presenta evidencias de descamación $(32 \% ; \mathrm{n}=32)$ del tejido cortical (Figura $4 \mathrm{~B})$. Asociado a los remanentes del mismo se observaron depositaciones de carbonato de calcio en $23,2 \%(n=38)$ de los restos. Respecto a las restantes variables, se identificó, en baja frecuencia, deterioro químico $(9,8 \% ; \mathrm{n}=16)$, marcas de raíces $(5,5 \% ; \mathrm{n}=9)$ y de roedores $(4,9 \% ; n=8)$. En relación con los indicadores de la posible acción humana se registró alteración térmica en un 9,8\% $(n=16)$ de los restos. Entre estos, 11 especímenes se encuentran calcinados (escápula, radio, cúbito, fémur, tibia, astrágalo, vértebras) y cinco quemados (húmero, cúbito, tibia, metatarsos). El porcentaje de completitud para el conjunto de M. coypus fue de $29,4 \%$. Gran parte de las fracturas (87\%) se corresponden con causas post-depositacionales, en tanto el porcentaje restante es de difícil asignación ya que sus bordes se presentan altamente redondeados y pulidos, posiblemente como consecuencia de la erosión eólica.

En los que respecta al conjunto de excavación, $M$. coypus está representado por escasos elementos del esqueleto axial (una vértebra lumbar, una vértebra caudal, tres fragmentos de incisivos y un molar aislado) y del esqueleto apendicular (una falange). Estos restos muestran depositaciones de carbonato de calcio en cinco casos. Dos especímenes presentan meteorización correspondiente al estadio 1, en la misma cantidad de elementos se observaron improntas de raíces. El deterioro químico se registró en un espécimen y en un único caso se identificó termoalteración (incisivo carbonizado).

\section{$\underline{\text { Roedores }<1 \mathrm{~kg}}$}

En el conjunto de superficie, la abundancia relativa de estos roedores se calculó de manera conjunta considerando la totalidad de los taxa $(\mathrm{MNI}=148)$. El promedio de la misma fue de $20,4 \%$. Los elementos con mejor representación corresponden a hemimandíbulas $(96,3 \%$; $\mathrm{MNE}=285)$, cráneos $(83,1 \%$; $\mathrm{MNE}=123)$ e incisivos aislados $(54,7 \% ; \mathrm{MNE}=324)$. En lo que respecta al esqueleto apendicular, el fémur $(34,1 \% ; \mathrm{MNE}$ $=101)$ y el húmero $(23,3 \% ; \mathrm{MNE}=69)$ son los que registran las mayores frecuencias. Los restantes elementos se encuentran representados en porcentajes menores. Los índices que evalúan las proporciones de determinados elementos y porciones anatómicas muestran un predominio de elementos craneales (PCRT/CR $=38,4)$ y una destrucción preferencial de elementos distales $(\mathrm{Z} / \mathrm{E}=43,5)$.

La principal modificación que se observó sobre las superficies óseas fue consecuencia de la abrasión eólica $(33,5 \% ; n=790)$ la cual se presenta como un leve pulido del 
tejido cortical. Las tinciones de manganeso fueron identificadas en 257 huesos (10,9\%), aunque en la mayoría de estos $(\mathrm{n}=223)$ el porcentaje de la superficie afectada es bajo (0-25\%). En cuanto a la incidencia de la meteorización 185 (7,8\%) especímenes fueron atribuidos al estadio $1,18(0,8 \%)$ al estadio 2 y $12(0,5 \%)$ al estadio 3 . Las depositaciones de carbonato de calcio e improntas de raíces se registraron en $7,2 \%$ de los restos y con un bajo porcentaje de la superficie afectada en la mayoría de los casos. El 3,6\% ( $\mathrm{n}=85)$ mostró descamación y un 2,3\% $(n=55)$ presentó evidencias de deterioro químico. Asimismo, se identificaron marcas de dientes de carnívoros en 37 especímenes óseos $(1,1 \%)$ correspondientes a Rodentia indeterminado, Ctenomys sp. y R. auritus. En todos los casos se reconocieron perforaciones y hoyuelos, en un resto se observó la presencia de arrastres y en otro de borde crenulado. En porcentajes muy bajos se registraron elementos con marcas de roedores y pisoteo $(0,1 \%$ y $0,04 \%$, respectivamente).

La presencia de trazas digestivas se registró en un bajo porcentaje $(1,6 \% ; n=21)$. Entre los dientes se identificó un incisivo in situ de Ctenomys sp. y dos molares aislados de este género con evidencias de digestión moderada (Figura 6A). Para este mismo taxón se registró un molar aislado con corrosión fuerte. A esto se suma una maxila de $R$. auritus cuyos molares muestran marcas de digestión fuertes (Figura 6B). En el caso del postcráneo, la mayor frecuencia de trazas digestivas se registró en el fémur (11 epífisis proximales con evidencias de digestión ligera y cinco moderada), mientras que solo una epífisis distal de húmero presentó corrosión moderada.

Las evidencias de termoalteración se identificaron en bajo porcentaje $(2,6 \% ; n=61)$. La mayor parte se presenta en restos atribuidos a la Subfamilia Caviinae, de los cuales 23 especímenes se encuentran calcinados, siete quemados y cuatro carbonizados. Entre estos, los principales elementos afectados corresponden a restos craneales y calcáneos. Los restantes elementos termoalterados pertenecen al Orden Rodentia indeterminado y en su mayoría se encuentran quemados. Entre los cricétidos, se recuperó solo un resto calcinado.

En lo que respecta a la fragmentación del conjunto, el porcentaje de completitud fue de 20,1\%. Entre los huesos largos fragmentados predominan aquellos que presentan superficies de fractura con ángulos agudos y bordes ásperos $(87,1 \%)$ por lo que se les atribuye un origen post-depositacional. El porcentaje restante muestra las superficies redondeadas y pulidas, aspecto que dado el contexto es difícil precisar si es consecuencia de la acción digestiva, de la abrasión eólica y/o de una combinación de ambos procesos.

En el conjunto de excavación, el cálculo de la abundancia relativa también se llevó a cabo de manera conjunta $(\mathrm{MNI}=9)$. El promedio de la misma fue de $18,3 \%$. Entre los elementos mejor representados se encuentran los cráneos $(88,9 \% ; \mathrm{MNE}=8)$ y las hemimandíbulas $(61,1 \% ; \mathrm{MNE}=11)$. Le siguen el fémur, con una representación media $(50 \% ; \mathrm{MNE}=9)$, el húmero $(38,9 \% ; \mathrm{MNE}=7)$ y el calcáneo $(27,8 \% ; \mathrm{MNE}=5)$. Los elementos restantes se encuentran representados en frecuencias menores. Esto está en consonancia con los índices cuyos valores reflejan un predominio de elementos craneales $(\mathrm{PCRT} / \mathrm{CR}=55,2)$ y una perdida preferencial de elementos distales $(\mathrm{Z} / \mathrm{E}=25)$.

La principal modificación registrada sobre las superficies óseas corresponde a las depositaciones de carbonato de calcio $(47,8 \% ; \mathrm{n}=55)$, seguida por las marcas de raíces $(30,4 \% ; n=35)$. En menor frecuencia se observó la presencia de deterioro químico $(16,5 \% ; n=19)$ y tinciones de manganeso $(9,6 \% ; n=11)$. Las evidencias de meteorización y de abrasión se identificaron en un solo resto. Asimismo, se registró un incisivo aislado de Rodentia indeterminado con marcas de digestión fuerte. Por último, cuatro especímenes de Caviinae presentaron evidencias de termoalteración (dos hemimaxilas quemadas y una hemimaxila y un calcáneo calcinados). Este conjunto también presenta una elevada fragmentación. El porcentaje de completitud 


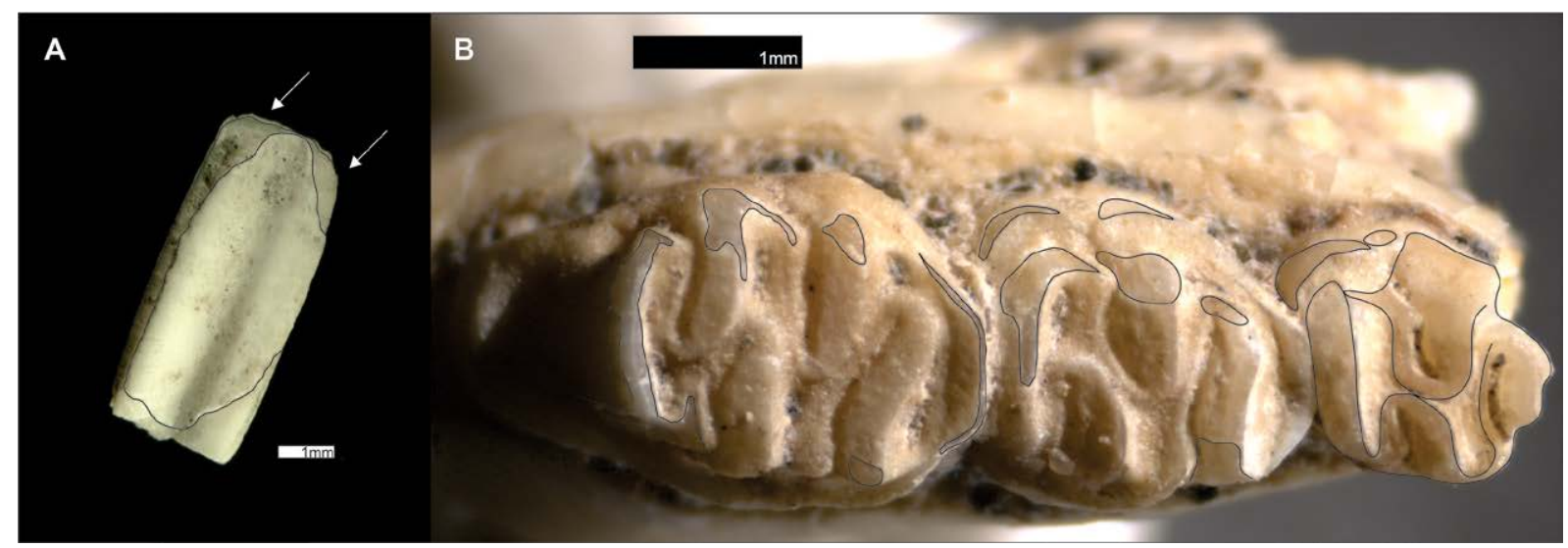

Figura 6. A) Molar aislado de Ctenomys sp. con evidencia de corrosión digestiva moderada. B) Maxila de R. auritus con evidencia de corrosión digestiva fuerte.

fue de 26,8\%. Las superficies de fractura presentan ángulos agudos y bordes ásperos permitiendo atribuirles un origen post-depositacional.

\section{Los armadillos}

En el caso de los armadillos, la muestra procedente de superficie está compuesta por 536 restos, entre los cuales la mayor parte $(n=461)$ corresponde a placas dérmicas. A nivel taxonómico se identificó la presencia de Zaedyus pichiy $(42 \%$; $\mathrm{MNI}=2)$, mayormente representado por placas dérmicas $(81,8 \%)$. Además, se recuperaron restos correspondientes a Chaetophractus villosus aunque en frecuencias menores $(8,4 \% ; \mathrm{MNI}=1)$. En este caso, las placas dérmicas también dominan el conjunto $(82,2 \%)$.

En relación con la representación anatómica del endoesqueleto, el promedio de la abundancia relativa es de $25,8 \%$. Los elementos mejor representados son el cúbito ( $83,3 \%$; $\mathrm{MNE}=5)$, la tibia $(66,7 \%$; $\mathrm{MNE}=4)$, el fémur y la mandíbula, ambos con frecuencias semejantes $(50 \% ; \mathrm{MNE}=3)$. Le siguen la escápula, el radio y el astrágalo con el 33,3\% $(\mathrm{MNE}=2)$. Los restantes elementos se encuentran en porcentajes menores, a excepción del cráneo y las costillas que no están representados. El principal proceso que afectó a los restos fue la abrasión eólica. En este sentido, el 66,7\% $(n=50)$ de los especímenes presenta la superficie pulida y esculpida. Asimismo, se registraron evidencias de meteorización en el 33,3\% $(n=25)$ de los casos, en su mayoría correspondientes al estadio $1(n=18)$. En un $24 \%(n=18)$ se observó descamación del tejido cortical. Sumado a esto, se hallaron restos con depositaciones de manganeso $(22,7 \% ; n=17)$ y carbonato de calcio $(12 \%$; $\mathrm{n}=9$ ). En cinco restos se identificaron evidencias de deterioro químico, mientras que dos especímenes presentaron marcas de roedores. Las improntas de raíces y marcas de dientes de carnívoros fueron halladas en un solo resto.

Entre las posibles modificaciones de origen antrópico se detectaron 14 elementos del endoesqueleto con evidencias de alteración térmica, la mayoría de los cuales corresponden a restos postcraneales (e.g. vértebras, tibia, metapodio, cúbito y radio). Entre estos, siete se encuentran quemados, cuatro carbonizados y tres calcinados. A estos se suman 33 placas dérmicas que muestran algún grado de termoalteración, gran parte de las cuales se encuentran completamente calcinadas $(n=21)$. Los restantes casos presentan ambas caras quemadas o carbonizadas o solo la cara externa afectada. El porcentaje de completitud de este conjunto fue del 53,3\%. En todos los casos las fracturas son de origen postdepositacional. 
En el conjunto de excavación se recuperaron 79 especímenes a partir de los cuales se pudo estimar la presencia de al menos un individuo de Z. Pichiy. La mayor parte de los restos corresponden a placas dérmicas $(n=76)$. Se recuperaron solo tres elementos del endoesqueleto: un metapodio y un hueso del basipodio, completos y un fragmento de cóndilo mandibular. Estos restos mostraron presencia de carbonato de calcio y en un caso manganeso y meteorización. Las evidencias de termoalteración se identificaron solo en cuatro placas dérmicas, de las cuales dos se encuentran quemadas, una carbonizada y otra calcinada en ambas caras.

\section{Los carnívoros y marsupiales}

Estos grupos de mamíferos son los que presentan las frecuencias más bajas dentro de los conjuntos (Tabla 1). Los carnívoros solo están representados en la muestra de superficie ( $\mathrm{n}=3$, falange, astrágalo y vértebra caudal). En estos restos se observó descamación del tejido cortical, abrasión, tinciones de manganeso, meteorización (estadio 1) y depositaciones de carbonato de calcio.

Entre los marsupiales, en el conjunto de superficie se recuperaron ocho especímenes atribuidos a la Familia Didelphidae. La mayor parte de estos corresponde a hemimandíbulas pertenecientes a alguna especie de marmosino de pequeño tamaño ( $c f$. Thylamys sp.; $\mathrm{n}=7 ; \mathrm{MNI}=2$ ). Solo un espécimen fue identificado como perteneciente a Didelphis albiventris. En cinco casos las superficies óseas presentaron evidencias de meteorización, correspondientes a los estadios más bajos y en tres, descamación del tejido cortical. Las restantes variables (abrasión, raíces y deterioro químico) fueron registradas en exiguos casos. En el conjunto de excavación se recuperó una hemimaxila de un marsupial pequeño (cf. Thylamys sp.). Dicho espécimen sólo presentó depositaciones de carbonato de calcio.

\section{Interpretación del conjunto faunístico}

En el conjunto de fauna menor del sitio LMO se identificaron con distinto grado de especificidad y en frecuencias variables, aves medianas, reptiles, anfibios, roedores de pequeño y gran tamaño, armadillos, marsupiales y carnívoros. La mayor parte de los elementos de estos vertebrados menores, al igual que ocurre con el resto de los materiales del sitio, se recuperaron en superficie, es por esto que, en general, las principales tendencias obtenidas derivan de este contexto. Sin embargo, es importante notar que el material que proviene de estratigrafía, si bien se presenta en baja frecuencia, muestra características similares al conjunto de superficie en términos de representación taxonómica, grado de fragmentación y variables tafonómicas registradas.

El análisis de los efectos tafonómicos mostró que existen diferencias entre los diversos taxa con respecto a la presencia y a la intensidad con la que se manifiestan las distintas modificaciones. Por un lado, se encuentran los restos correspondientes a roedores de mayor tamaño como el coipo, algunos especímenes de aves medianas y de armadillos. Estos fueron intensamente abradidos producto de la erosión eólica. En este sentido, presentan las superficies óseas pulidas y/o esculpidas y los bordes anatómicos redondeados. Asimismo, un porcentaje importante de estos elementos mostró descamación de la superficie ósea la cual, como se expuso previamente, se presenta como una exfoliación del tejido cortical sin agrietamiento previo que deja pequeños remanentes de la capa más externa del hueso. Estos suelen estar asociados a concreciones de sedimento y/o carbonato de calcio (Figura 4A-B). De igual manera, la meteorización fue otra de las variables que influyó considerablemente sobre los restos de este conjunto. Si bien la mayor frecuencia corresponde a los estadios más bajos, se debe considerar que en casos como el de las aves, 
la escasa representación de los estadios más avanzados puede ser resultado de la rápida destrucción de los restos una vez que alcanzan el estadio 1 (Behrensmeyer et al., 2003; Cruz, 2008; Muñoz y Savanti, 1998). Otras variables registradas sobre estos especímenes fueron las tinciones de manganeso, marcas de raíces y, en porcentajes menores, deterioro químico y marcas de roedores. Estas modificaciones se incrementan en los escasos restos provenientes de excavación.

Por otro lado, una situación diferente se observa en los elementos atribuidos a especies de roedores de pequeño tamaño $(<1 \mathrm{~kg})$ tales como Ctenomys sp., cricétidos y algunos cávidos, marsupiales, anfibios, reptiles y ciertos especímenes correspondientes a armadillos. Si bien en este caso también gran parte de los restos fueron modificados por la abrasión eólica, ésta solo se presenta como un pulido de la superficie que le otorga a la misma un aspecto brilloso. Además, algunos de los especímenes exhiben descamación, tinciones de manganeso e impresiones radiculares. Sin embargo, las frecuencias con las que se presentan son bajas en comparación al conjunto mencionado anteriormente. Asimismo, observaciones realizadas durante los trabajos de campo (presencia de individuos completos o partes articuladas y en posición anatómica, sumado al aspecto y coloración de las superficies) sugieren que parte de los restos de estos taxa responde a acumulaciones recientes.

A partir de lo descripto, se observa que los restos recuperados en el sitio pueden ser agrupados en dos grandes conjuntos que sugieren dos historias tafonómicas: por un lado, las modificaciones observadas en los restos de coipo, aves y algunos de armadillos sugieren que estos habrían formado parte del contexto de depositación del Holoceno medio y habrían estado sometidos a la alternancia de procesos de enterramiento y de re-exposición producto de la propia dinámica de los médanos. En este caso, la presencia de óxido de manganeso, carbonato de calcio e impresiones radiculares indicarían que estos restos estuvieron enterrados. De igual manera, la descamación que muestran algunos de los huesos puede ser consecuencia del contacto con alguna clase de ambiente corrosivo (Matthews, 2004). En este sentido, los sedimentos con $\mathrm{pH}$ altamente alcalino pueden producir este tipo de modificación (Fernández- Jalvo et al., 1998, Fernández-Jalvo, Sánchez-Chillon, Andrews, Fernández-López y Alcalá Martínez, 2002; Matthews, 2004). Esto cobra sentido, si se tiene en cuenta que los valores de $\mathrm{pH}$ del sedimento recuperado en las excavaciones indican condiciones moderadas a fuertemente alcalinas $(8,2$ a 9,6; G. A. Martínez, comunicación personal, 2019), lo cual refuerza la idea de que al menos parte de estos restos habrían estado enterrados. Asimismo, como consecuencia de la re-exposición, los huesos se habrían visto sometidos a la acción prolongada de la abrasión eólica y la meteorización. Un escenario similar fue propuesto por Stoessel (2015) a partir del análisis de los restos de peces (i. e. perca) recuperados en este sitio. Sin embargo, más allá de lo hasta aquí expuesto, es necesario considerar la complejidad del contexto de proveniencia de estos materiales. En este sentido, al tratarse de un sitio donde los restos se encuentran mayormente distribuidos en superficie, dichas depositaciones pueden representar acumulaciones de diferentes momentos. Esta situación hace necesario que, además de un exhaustivo análisis tafonómico, se lleve a cabo un programa de dataciones para evaluar la amplitud del proceso de acumulación involucrado (Oria, Salemme y Vázquez, 2016). Vinculado a esto, el fechado sobre una maxila de coipo que coincide con las demás dataciones para el sitio, realizadas sobre restos óseos humanos y de guanaco, refuerza la propuesta de que algunas de estas especies de fauna menor habrían formado parte del contexto de depositación del Holoceno medio.

Un escenario distinto muestra la mayor parte de los restos de roedores pequeños, marsupiales, anfibios, reptiles y algunos especímenes de armadillos. Las modificaciones observadas en las superficies de los mismos, así como el aspecto de muchos de estos (i.e. coloración que denota un origen reciente) indican que se corresponden preferentemente con acumulaciones actuales. 
El otro punto a considerar en la interpretación del ensamble faunístico aquí analizado, está vinculado con las causas que dieron origen a la presencia de los diversos restos de fauna menor presentes en el sitio. En este sentido, entre los taxa que estarían vinculados al contexto de depositación del Holoceno medio (i. e. coipo, aves medianas $y$, posiblemente, armadillos) se identificaron algunos indicadores que pueden atribuirse a la acción antrópica sobre los mismos. Entre estos, se puede mencionar la presencia de una huella de corte en un esternón de ave mediana (Figura 5). Si se tiene en cuenta el sector anatómico en el que se encuentra, el cual está ligado a una de las regiones con mayor contenido cárnico y al sostenimiento de los músculos pectorales (Tivoli y Pérez, 2009), es posible sugerir su asociación con acciones de descarne sobre la presa. En este caso, es necesario mencionar que la intensa abrasión a la que se vieron sometidos los restos una vez expuestos pudo haber enmascarado la potencial presencia de huellas y, en consecuencia, afectar su posterior identificación. Vinculado con esto, se puede señalar el caso de los especímenes de perca recuperados en este sitio. Stoessel (2015) identificó varias marcas transversales en los cuerpos vertebrales de esta especie que se corresponden con huellas de procesamiento. Sin embargo, no presentan los atributos característicos de una huella de corte producto principalmente de la abrasión de los especímenes. En este caso, fue la localización y recurrencia de las incisiones, la comparación con el registro de otros sitios y los estudios experimentales los que permitieron sugerir que se corresponden con huellas de origen antrópico (Stoessel, 2015).

Las evidencias de alteración térmica constituyen otra de las modificaciones que pueden estar relacionadas con la actividad antrópica y que se registró, tanto en superficie como en excavación, preferentemente en los especímenes de aquellos taxa vinculados con el contexto de depositación del Holoceno medio (e.g., aves, M. coypus, Chlamyphoridae) $y$, entre los pequeños roedores, en los restos de Caviinae. Se observan diversos grados de alteración, aunque la mayor frecuencia corresponde a aquellos que se encuentran calcinados. Sin embargo, no se halló un patrón de modificación específico asociado con el tipo o porción del elemento afectado que se pueda atribuir a una práctica de cocción particular. En este sentido, diversas partes anatómicas se encuentran termoalteradas y, en general, toda la superficie se vio afectada de manera homogénea (Figura 4C). Estas características llevan a sugerir que, al menos parte de dicha modificación sería el resultado de causas ligadas con el descarte y/o procesos post-depositacionales tales como el contacto accidental con una fuente de calor cuando estaban en la superficie o haber sido enterrados en sedimentos cerca del fuego (Asmussen, 2009; Bennett, 1999; Pardiñas, 1999).

En el caso de los roedores de menor tamaño tales como Ctenomys sp. y Cricetidae, son varios los indicadores que señalan un origen natural de la muestra. Entre los más claros se encuentran las marcas de carnívoros, las cuales solo fueron identificadas en restos de estos taxa, a excepción de un espécimen de Chlamyphoridae. Asimismo, se registraron evidencias de corrosión digestiva en diversos grados. Esto lleva a sugerir la participación de mamíferos carnívoros y potencialmente aves rapaces diurnas (Accipitriformes y/o Falconiformes) en la generación del conjunto. La representación de partes esqueletarias registrada apoya un origen depredacional. En este sentido, se observa una baja representación de restos postcraneales y de elementos distales, patrón que, como fue señalado por varios autores, caracteriza a muchas de las acumulaciones generadas por rapaces diurnas y carnívoros vinculado con la destrucción preferencial de estas porciones anatómicas durante la ingesta por parte de estos predadores (Andrews, 1990; Gómez, 2007; Montalvo, Bisceglia, Kin y Sosa, 2012; Montalvo, Fernández, Liébana, Santillán y Sarasola, 2014). Asimismo, al comparar las abundancias relativas generadas para el conjunto de roedores de LMO con el promedio obtenido por Andrews (1990) para Strigiformes y Falconiformes se observa que existe cierta similitud con las curvas de representación obtenidas para estas últimas (Figura 7). Una situación 


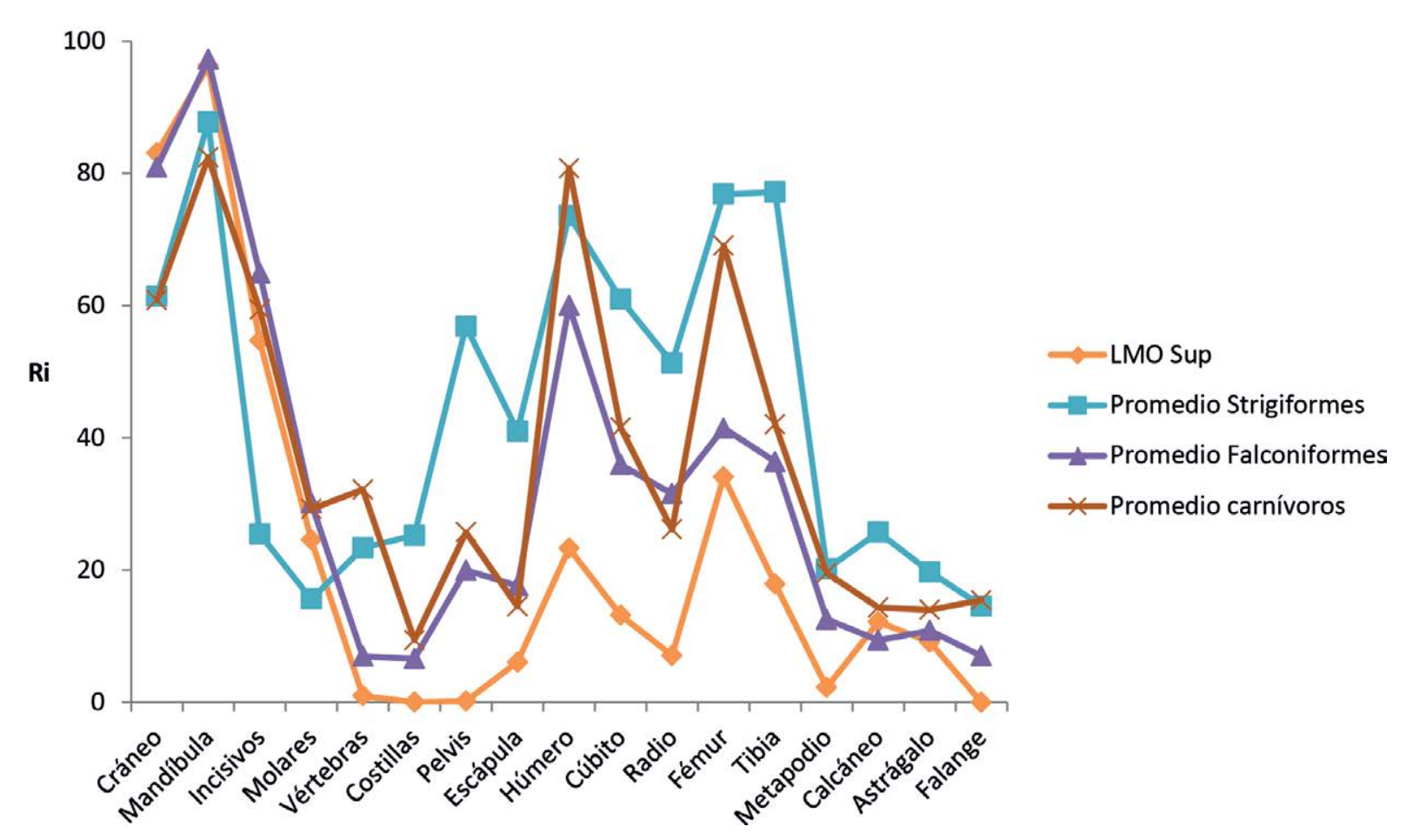

Figura 7. Comparación de las abundancias relativas (Ri) del conjunto de roedores ( $<1 \mathrm{~kg}$ ) de superficie del sitio La Modesta y el promedio de Strigiformes, Falconiformes y carnívoros generado por Andrews (1990).

similar se percibe al realizar la comparación con los valores de abundancia relativa promedio de fecas de mamíferos carnívoros generado por Andrews (1990) (Figura 7). Sumado a esto, se debe considerar que, dado que el entorno donde se emplaza el sitio constituye un ambiente propicio para el desarrollo de cuevas por parte de roedores fosoriales, la presencia de roedores de tamaño pequeño también puede responder a muertes naturales in situ (sin la intervención de un predador). Esto daría cuenta, de manera complementaria, de las altas proporciones de Ctenomys sp. en el conjunto.

\section{Discusión}

En síntesis, a partir de las tendencias obtenidas de los estudios tafonómicos y del análisis del contexto de depositación se observa que el conjunto faunístico de LMO es el resultado de complejas historias tafonómicas. Esto, sumado a la baja integridad que presenta el sitio dificulta las interpretaciones acerca de las interacciones que tuvieron lugar entre los grupos humanos y las diversas especies faunísticas identificadas. Sin embargo, a partir de los resultados aquí presentados y la información ya generada para el sitio es posible delinear algunos aspectos acerca de la subsistencia de los grupos cazadores-recolectores que ocuparon el interior del área de estudio durante, al menos, parte del Holoceno medio.

Los resultados obtenidos en este trabajo muestran que además de los peces fluviales y especies de tamaño mayor, como el guanaco (Martínez et al., 2014; Stoessel, 2015), otras especies de fauna menor, como M. coypus, aves medianas y, posiblemente armadillos, habrían contribuido a la dieta de las poblaciones humanas. Asimismo, la información derivada de los análisis de isótopos estables en restos óseos humanos de este sitio indica dietas preferentemente terrestres (Flensborg et al., 2018). Sin embargo, se debe agregar que los valores isotópicos provenientes de los sitios localizados en la costa (i.e. Tres Bonetes 1 y Cantera de Rodados Villalonga), con cronologías en torno a ca. 5300-4900 
años AP, dan cuenta de dietas mixtas a preponderantemente marinas (Flensborg et al., 2018). De esta manera, la evidencia disponible hasta el momento indica que durante el Holoceno medio, diversas especies habrían formado parte de la dieta de las poblaciones humanas que habitaron este sector de la transición pampeano patagónica oriental, las cuales involucran entornos fluviales, terrestres y marinos. No obstante, se debe resaltar que, como se expuso a lo largo de este trabajo, el material arqueofaunístico de este periodo procede de contextos altamente disturbados. Particularmente, en el caso del sito LMO, los restos provienen de un contexto superficial muy dinámico caracterizado por procesos de erosión y re-depositación. La acción constante y prolongada en el tiempo de dichos procesos condicionó la configuración y composición de los conjuntos faunísticos pudiendo implicar una preservación diferencial de elementos de las distintas especies (Martínez et al., 2017a; Stoessel, 2015). Esto dificulta, en algunos casos, la confirmación del consumo humano de ciertos taxa, como así también la evaluación de la importancia que cada uno de estos habría tenido en la subsistencia. Por el momento, si bien no se pueden establecer patrones y modalidades de consumo sobre determinadas especies, los análisis tafonómicos y los fechados obtenidos permiten realizar una primera aproximación a la subsistencia de este periodo y aportar datos novedosos sobre el consumo de ciertas especies de fauna menor para momentos sobre los cuales no se contaba con dicha información.

En una escala espacial mayor, si se consideran aquellas áreas tanto de la región pampeana, como de norpatagonia oriental que cuentan con registros faunísticos con cronologías del Holoceno medio (6500-3000 años AP), se observa que la fauna menor constituyó un recurso explotado recurrentemente (Álvarez, Alcaráz, Gutiérrez y Martínez, 2013; Frontini, 2013; Mazzanti, Martínez y Quintana, 2015; Scartascini, 2014). Asimismo, se observan diferencias entre las especies aprovechadas en función de la localización de los sitios. En lo que respecta al sector costero se registró el aprovechamiento de peces marinos como corvina negra (Pogonias cromis: Barrio las Dunas, Bayón, Frontini y Vecchi, 2012; Frontini, 2013), de aves medianas como pingüinos y de dasipódidos (Alfar: Bonomo y Leon, 2010). Un caso particular se presenta en la costa norte del golfo San Matías donde los peces marinos constituyeron un recurso importante en la subsistencia durante el lapso ca. 6000-4000 años AP (Favier Dubois y Scartascini, 2012; Scartascini, 2014). Por el contrario, los asentamientos ubicados en el interior muestran la explotación de especies de origen continental exclusivamente, tales como armadillos y roedores grandes como la vizcacha (e.g., El Puente; niveles inferiores de Paso Mayor Y1 S1; El Guanaco; Paso Otero 3, Las Toscas 5; Laguna Muscar 2 -Bayón, Pupio, Frontini, Vecchi y Scabuzzo, 2010; Bellinzoni, 2018; Martínez, 2006; Messineo, Kaufmann, Steffan, Favier Dubois y Pal, 2014; Rodríguez, 2018; entre otros entre otros-) y, en algunas ocasiones, también tinámidos, carnívoros y reptiles (i.e. niveles superiores de Paso Otero 4; segunda ocupación de Cueva Tixi - Álvarez et al., 2013; Mazzanti et al., 2015-). En la mayoría de los casos, estos recursos de menor porte fueron el complemento de una dieta basada en el consumo de grandes mamíferos como los otáridos en la zona del litoral atlántico (Sanguinetti de Bórmida et al., 2000) y de ungulados en los sectores continentales (Álvarez et al., 2013; Bellinzoni, 2018; Frontini, 2013; Martínez, 2006; Mazzanti et al., 2015; Messineo et al., 2014; Rodríguez, 2018).

Si se tiene en cuenta la evidencia disponible para el curso inferior del río Colorado para este periodo y se la compara con lo hasta aquí mencionado para regiones aledañas, se observan algunas diferencias en cuanto a los taxa de fauna menor explotados. Como se dejó expuesto a lo largo del trabajo, para el área de transición pampeano-patagónica oriental los sitios con material faunístico se localizan al interior del área (entre 60-50 km de la costa) y, si bien presentan varias especies continentales con evidencias de consumo se destaca, en frecuencia, la explotación de recursos de origen fluvial, principalmente peces (i. e. perca, Stoessel, 2015). Por el contrario, en los sectores aledaños, el consumo de peces se registró solo en sitios ligados al litoral atlántico y corresponden en su totalidad a especies marinas (Bayón et al., 2012; Favier Dubois y Scartascini, 2012). 


\section{Conclusión}

Los estudios llevados a cabo en LMO sobre el conjunto óseo de fauna menor contribuyen a generar una primera aproximación acerca de la subsistencia de las poblaciones cazadoras-recolectoras durante el Holoceno medio en la transición pampeanopatagónica oriental. En función de la información disponible hasta el momento, se puede sugerir que la subsistencia de los grupos humanos durante este lapso habría estado caracterizada por el consumo de diversas especies entre las que se encuentran peces fluviales como la perca y otros taxa de fauna menor como el coipo, aves de mediano tamaño y, posiblemente, armadillos. A esto se suma el aporte de los ungulados y taxa marinos. En este sentido, se observa una complementariedad entre diferentes recursos que involucran diversos entornos. Sin embargo, se debe tener en cuenta que aún son escasos los sitios con cronologías de este período que cuentan con registro faunístico y por el momento la mayor parte de éste procede de contextos superficiales, lo cual también dificulta la evaluación del aporte que cada taxón habría tenido en la dieta. Análisis futuros a partir de la identificación de nuevos sitios y la ampliación de las muestras analizadas permitirán generar un panorama más claro de la subsistencia para este lapso.

\section{Agradecimientos}

Los análisis presentados en este trabajo forman parte de mi tesis doctoral la cual fue realizada en el marco de una beca otorgada por el Consejo Nacional de Investigaciones Científicas y Técnicas (CONICET). Los trabajos fueron financiados por ANPCYT (PICT n²42-2012) y National Geographic Society (Grant\#9756-15). Agradezco al INCUAPA-CONICET, FACSO-UNICEN por el apoyo institucional. A mis directores, Gustavo Martínez y María Gutiérrez y a Luciana Stoessel y Federico Scartascini por las lecturas y sugerencias realizadas sobre distintas versiones de este trabajo, como así también a dos evaluadores anónimos que contribuyeron a mejorar el manuscrito. A Cristian Kaufmann, Agustina Massigoge y Juan Manuel Capuano por la obtención de las fotografías en las lupas estereoscópicas. A Pablo Bayala por la realización del mapa. 


\section{Q Referencias citadas}

" Alcaráz, A. P. (2015a). Aprovechamiento antrópico de fauna menor en el curso inferior del río Colorado (transición pampeano-patagónica oriental): el sitio El Tigre como caso de estudio. Intersecciones en Antropología, 16, 115-129.

"Alcaráz, A. P. (2015b). Primeros resultados de los análisis del conjunto de fauna menor del sitio arqueológico Zoko Andi 1 (transición pampeano-patagónica oriental, provincia de Buenos Aires, Argentina). Archaeofauna, 24, 119-133.

"Álvarez, M. C., Alcaráz, A. P., Gutiérrez, M. A. y Martínez, G. (2013). Análisis zooarqueológico del sitio Paso Otero 4 (partido de Necochea). Aportes a la discusión de modelos de subsistencia de la región pampeana. Intersecciones en Antropología, 14, 383-398.

" Andrews, P. (1990). Owls. Caves and Fossils. Londres: The University of Chicago Press.

»Asmussen, B. (2009). Intentional or incidental thermal modification? Analysing site occupation via burned bone. Journal of Archaeological Science, 36, 528-536.

" Bayón, C., Pupio, A., Frontini, R., Vecchi, R. y Scabuzzo, C. (2010). Localidad arqueológica Paso Mayor: nuevos estudios 40 años después. Intersecciones en Antropología, 11, 115-128.

" Bayón, C., Frontini, R. y Vecchi, R. (2012). Middle Holocene settlements on coastal dunes, southwest Buenos Aires Province, Argentina. Quaternary International, 256, 54-61.

" Behrensmeyer, A. K. (1978). Taphonomic and ecologic information on bone weathering. Paleobiology, 4, 150-162.

» Behrensmeyer, A. K., Stayton, C. T. y Chapman, R. E. (2003). Taphonomy and ecology of modern avifaunal remains from Amboseli Park, Kenya. Paleobiology, 29, 52-70.

» Bellinzoni, J. (2018). Análisis zooarqueológico y tafonómico del sitio Laguna Muscar 2 (pdo. de General Lamadrid, pcia. de Buenos Aires). (Tesis de Licenciatura inédita), Universidad Nacional del Centro de la Provincia de Buenos Aires, Argentina.

" Bennett, J. L. (1999). Thermal Alteration of Buried Bone. Journal of Archaeological Science, $26,1-8$.

" Binford, L. R. (1981). Bones: Ancient Men and Modern Myths. Nueva York: Academic Press.

»Bochenski, Z. M. (2005). Owls, diurnal raptors and humans: signature on avian bones. En T. O'Connor (Ed.), Biosphere and Lithosphere. New studies in vertebrate taphonomy (pp. 31-45). Oxford: Oxbow Books.

"Bochenski, Z. M. y Tomek, T. (1997). Preservation of bird bones: erosion versus digestion by owls. International Journal of Osteoarchaeology, 7, 372-387.

" Bonomo, M. y Leon, D. C. (2010). Un contexto arqueológico en posición estratigráfica en los médanos litorales. El sitio Alfar (Pdo. de General Pueyrredón, Pcia. de Buenos Aires). En M. Berón, L. Luna, M. Bonomo, C. Montalvo, C. Aranda y M. Carrera Aizpitarte (Eds.), Mamul Mapü: pasado y presente desde la arqueología pampeana (Tomo 2, pp. 2945). Ayacucho: Libros del Espinillo.

» Carden, N. y Martínez, G. (2014). Diseños fragmentados. Circulación social de imágenes sobre huevos de Rheidae en Pampa y Norpatagonia. Boletín del Museo de Arte Precolombino, 19(2), 55-75.

"Cruz, I. (2008). Avian and Mammalian Bone Taphonomy in Southern Continental Patagonia. A Comparative Approach. Quaternary International, 180, 30-37. 
» Favier Dubois, C. M. y Scartascini, F. L. (2012). Intensive fishery scenarios on the North Patagonian coast (Río Negro, Argentina) during the Mid-Holocene. Quaternary International, 256, 62-70.

» Fernández, F. J., Montalvo, C. I., Fernández-Jalvo, Y., Andrews, P. y López, J. M. (2017). A re-evaluation of the taphonomic methodology for the study of small mammal fossil assemblages of South America. Quaternary Science Reviews, 155, 37-49.

» Fernández-Jalvo, Y. y Andrews, P. (2016). Atlas of Taphonomic Identifications. 1001+ Images of Fossil and Recent Mammal Bone Modification. Dordrecht: Springer.

» Fernández-Jalvo, Y., Denys, C., Andrews, P., Williams, T., Dauphin, Y. y Humphrey, L. (1998). Taphonomy and palaeoecology of Olduvai Bed I (Pleistocene, Tanzania). Journal of Human Evolution, 34, 137-172.

» Fernández-Jalvo, Y., Sánchez-Chillon, B., Andrews, P., Fernández-López, S. y Alcalá Martínez, L. (2002). Morphological taphonomic transformations of fossil bones in continental environments, and repercussions on their chemical composition. Archaeometry, 44, 353-361.

"Fisher, J. W. (1995). Bone Surface Modifications in Zooarchaeology. Journal of Archaeological Method and Theory, 2(1), 7-68.

» Flensborg, G., Martínez, G. y Tessone, A. (2018). First approach to the paleodiet of huntergatherers through stable isotopes $\left({ }_{13} \mathrm{C}\right.$ and ${ }_{15} \mathrm{~N}$ ) in the eastern Pampa-Patagonia transition during the Middle Holocene. Journal of Archaeological Science: Reports, 17, 571-580.

" Frontini, R. (2013). Aprovechamiento faunístico en entornos acuáticos del sudoeste bonaerense durante el Holoceno (6900-70o años AP). Relaciones de la Sociedad Argentina de Antropología, XXXVIII(2), 493-519.

» Frontini, R. y Vecchi, R. (2014). Thermal alteration of small mammal from El Guanaco 2 site (Argentina): An experimental approach on armadillos bone remains (Cingulata, Dasypodidae). Journal of Archaeological Science, 44, 22-29.

» Giardina, M. A. (2010). El aprovechamiento de la avifauna entre las sociedades cazadoras recolectoras del sur de Mendoza: un enfoque arqueozoológico. (Tesis Doctoral inédita), Universidad Nacional de La Plata, Argentina.

» Gómez, G. N. (2007). Predator categorizations upon micromammals bones and taphonomic analysis. A comparative study with proposed models. En M. A. Gutiérrez, L. Miotti, G. Barrientos, G. Mengoni Goñalons y M. Salemme (Eds.), Taphonomy and Archaeozoology in Argentina (pp. 89-103). Oxford: BAR International Series 1601, Archaeopress.

» Gutiérrez, M. A. (2004). Análisis tafonómicos en el Área Interserrana (provincia de Buenos Aires). (Tesis Doctoral inédita), Universidad Nacional de La Plata, Argentina.

» Johnson, E. (1985). Current developments in bone technology. En Schiffer M. B (Ed.), Advances in archaeological method and theory (Volumen 8, pp. 157-235). Nueva York: Academic Press.

» Lyman, R. (1994). Vertebrate Taphonomy. Cambridge: Cambridge University Press.

» Lyman, R. (2008). Quantitative Paleozoology. Nueva York: Cambridge University Press.

» Martínez, G. (2006). Arqueología del curso medio del río Quequén Grande: estado actual y aportes a la arqueología de la región pampeana. Relaciones de la Sociedad Argentina de Antropología, XXXI, 249-275.

» Martínez, G. (2017). Síntesis de los sitios y localidades arqueológicas. Resumen del modelo propuesto para el área de estudio. En G. Martínez (Ed.), Arqueología de Cazadores-Recolectores del curso inferior del río Colorado (Provincia de Buenos Aires, Argentina). Aportes al conocimiento de las ocupaciones humanas Pampeano-Patagónicas (pp. 45-67). Olavarría: INCUAPA-CONICET, UNICEN. 
» Martínez, G. y Flensborg, G. (2018). Nuevos contextos funerarios en la transición pampeano-patagónica oriental (pcia. de Buenos Aires, Argentina): aportes al Holoceno medio y tardío inicial. Chungara. Revista de Antropología Chilena, 5o(3), 441-458.

» Martínez, G., Alcaráz, A. P., Santos Valero, F., Stoessel, L., Flensborg, G., Martínez, G. A. y Carden, N. (2014). Sitios del Holoceno Medio en la transición pampeano- patagonica oriental (pdo. de Patagones, pcia. de Buenos Aires). Trabajo presentado en el VII Congreso de Arqueología de la Región Pampeana Argentina, Rosario, Santa Fe.

» Martínez, G., Flensborg, G., Alcaráz, A. P., Santos Valero, F., Stoessel, L., Martínez, G. A. y Owen, L. A. (2017a). La estructura del registro arqueológico del Holoceno medio en el curso inferior del río Colorado (Transición pampeano-patagónica oriental). Trabajo presentado en las X Jornadas de Arqueología de la Patagonia, Puerto Madryn, Argentina.

» Martínez, G., Stoessel, L., Flensborg, G., Alcaráz, A. P., Santos Valero, F., Martínez, G. A. y Owen, L. (2017b). Archaeological occupations of the Mid-Holocene in the Eastern Pampa-Patagonia transition, Argentina. Informe final entregado a National Geographic Society, Grant Number 9756-15. Manuscrito inédito.

»Matthews, T. (2004). The taxonomy and taphonomy of Mio-Pliocene and Late Middle Pleistocene micromammals from the Cape west coast, South Africa. (Tesis Doctoral inédita). Universidad de Cape Town, Sudáfrica.

»Mazzanti, D. L., Martínez, G. A. y Quintana, C. A. (2015). Asentamientos del Holoceno medio en Tandilia oriental. Aportes para el conocimiento de la dinámica poblacional de la Región Pampeana, Argentina. Relaciones de la Sociedad Argentina de Antropología, $\mathrm{XL}(1), 209-231$.

» Messineo, P. G., Kaufmann, C., Steffan, P. G., Favier Dubois, C. y Pal, N. (2014). Ocupaciones humanas en un valle intraserrano del sector noroccidental de Tandilia: sitio El Puente (Partido de Olavarría, Buenos Aires). Relaciones de la Sociedad Argentina de Antropología, XXXIX(2), 435-462.

» Montalvo, C., Bisceglia, S., Kin, M. S. y Sosa, R. A. (2012). Taphonomic analysis of rodent bone accumulations produced by Geoffroy's cat (Leopardus geoffroyi, Carnivora, Felidae) in Central Argentina. Journal of Archaeological Science, 39, 1933-1941.

» Montalvo, C. I., Fernández, F. J., Liébana, M. S., Santillán, M. y Sarasola, J. H. (2014). Taphonomic analysis of rodent bone accumulations produced by the White-tailed Kite (Elanus leucurus, Accipitriformes) in Central Argentina. Journal of Archaeological Science, $52,354-362$.

» Muñoz, A. S. y Savanti, F. (1998). Observaciones tafonómicas sobre restos avifaunísticos de la costa noreste de Tierra del Fuego. Revista del Museo de Historia Natural de San Rafael (Mendoza), XX(1/2), 107-121.

» Oria, J., Salemme, M. y Vázquez, M. (2016). Site formation processes in relation to surface bone assemblages in the Fuegian steppe (Tierra del Fuego, Argentina). Archaeological and Anthropological Sciences, 8(2), 291-304.

»Pardiñas, U. F. J. (1999). Tafonomía de microvertebrados en yacimientos arqueológicos de Patagonia (Argentina). Arqueología, 9, 265-340.

» Pinto Llona, A. C. y Andrews, P. (1999). Amphibian taphonomy and its application to the fossil record of Dolina (middle Pleistocene, Atapuerca, Spain). Paleoecology, 149, 411-429.

»Rodríguez, J. M. (2018). Análisis faunístico del sitio Las Toscas 5 (Tres Arroyos, provincia de Buenos Aires): Contribución al conocimiento de la subsistencia de cazadores recolectores pampeanos en el Holoceno medio. Intersecciones en Antropología, 19(1), 49-6o. 
» Salemme, M., Escosteguy, P. y Frontini, R. (2012). La fauna de porte menor en sitios arqueológicos de la región pampeana, Argentina. Agente disturbador vs. recurso económico. Archaeofauna, 21, 163-185.

»Sanguinetti de Bórmida, A., Weiler, N., Aldazabal, V., Curzio, D., Nami, H., Silveira, M. y Eugenio, E. (200o). Arqueología de la Costa Atlántica Septentrional: nuevas perspectivas. En Actas del III Congreso Argentino de Americanistas, 317-350, Buenos Aires.

»Santos Valero, F. (2017). La gestión de rocas a través del tiempo: aportes al estudio de la tecnología lítica durante el Holoceno medio y tardío en el valle inferior del río Colorado (provincia de Buenos Aires). (Tesis Doctoral inédita), Universidad Nacional del Centro de la Provincia de Buenos Aires, Argentina.

"Scartascini, F. L. (2014). Arqueología de la pesca en la costa Rionegrina. Patagonia Argentina. (Tesis Doctoral inédita), Universidad de Buenos Aires, Argentina.

»Stahl, P. W. (1996). The recovery and Interpretation of Microvertebrate Bone Assemblages from Archaeological Contexts. Journal of Archaeological Method and Theory, 3, 31-75.

»Stoessel, L. (2012). Consumo de peces en el área ecotonal árida-semiárida del curso inferior del río Colorado (Provincia de Buenos Aires) durante el Holoceno tardío. Relaciones de la Sociedad Argentina de Antropología, XXXVII, 159-182.

» Stoessel, L. (2015). Tendencias preliminares sobre el consumo de peces durante el Holoceno medio en el área de transición pampeano-patagónica oriental (Pcia. de Buenos Aires). Archaeofauna, 24, 103-117.

" Tivoli, A. y Peréz, A. (2009). Rendimiento económico del cauquén común (Chloephaga picta, Familia Anatidae). En M. Salemme, F. Santiago, M. Álvarez, E. Piana, M. Vázquez y M. E. Mansur (Eds.), Arqueología de Patagonia: una mirada desde el último confín (Tomo 2, pp. 853-864). Ushuaia: Editorial Utopías. 